\title{
GEOTHERMAL RESEARCH AND DEVELOPMENT PROGRAM
}

QUARTERLY TECHNICAL REPORT

July 1992 through September 1992

RECEIVED

MAR 041993

OSTI

\section{DISCLAIMER}

This report was prepared as an account of work sponsored by an agency of the United States Government. Neither the United States Government nor any agency thereof, nor any of their employees, makes any warranty, express or implied, or assumes any legal liability or responsibility for the accuracy, completeness, or usefulness of any information, apparatus, product, or process disclosed, or represents that its use would not infringe privately owned rights. Reference herein to any specific commercial product, process, or service by trade name, trademark, manufacturer, or otherwise does not necessarily constitute or imply its endorsement, recommendation, or favoring by the United States Government or any agency thereof. The views and opinions of authors expressed herein do not necessarily state or reflect those of the United States Government or any agency thereof.

Work Performed Under Grant No. DE-FG07-90ID12934

For

U. S. Department of Energy

Office of Industrial Technologies

Washington, D.C.

\section{By}

Standford Geothermal Program

Stanford University

Stanford, California $94305-2220$ 


\section{DISCLAIMER}

This report was prepared as an account of work sponsored by an agency of the United States Government. Neither the United States Government nor any agency Thereof, nor any of their employees, makes any warranty, express or implied, or assumes any legal liability or responsibility for the accuracy, completeness, or usefulness of any information, apparatus, product, or process disclosed, or represents that its use would not infringe privately owned rights. Reference herein to any specific commercial product, process, or service by trade name, trademark, manufacturer, or otherwise does not necessarily constitute or imply its endorsement, recommendation, or favoring by the United States Government or any agency thereof. The views and opinions of authors expressed herein do not necessarily state or reflect those of the United States Government or any agency thereof. 


\section{DISCLAIMER}

Portions of this document may be illegible in electronic image products. Images are produced from the best available original document. 


\title{
Quarterly Report for July - September 1992
}

\author{
Stanford Geothermal Program \\ Stanford University
}

November 3, 1992

\section{ADSORPTION OF WATER VAPOR ON RESERVOIR ROCKS}

This experimental project is under the direction of Research Associate Dr. Shubo Shang, and Prof. Henry J. Ramey, Jr. The focus of the work is the experimental investigation of adsorption of water onto geothermal reservoir rocks.

The results of water adsorption/desorption test performed on Geysers shallow reservoir core were reported in the Stanford Geothermal Program Second Annual Technical Report (1992). Using the same procedures described previously, adsorption/desorption isotherms of water vapor on Berea sandstone and Monteverdi \#2 sample were measured on the PMI Sorptometer. The results of these tests are summarised in this report.

Figures 1 and 2 show the isotherms obtained on Berea sandstone at 120 and $140^{\circ} \mathrm{C}$, respectively.

Figure 3 compares the adsorption isotherms obtained on the same sample at temperatures of 100,120 and $140^{\circ} \mathrm{C}$.

Figures 4 and 5 show the adsorption/desorption isotherms on Monteverdi \#2 sample at temperatures of 120 and $140^{\circ} \mathrm{C}$.

Figure 6 compares the adsorption isotherms obtained on this sample at $80,100,120$ and $140^{\circ} \mathrm{C}$.

As shown in Figures 1 to 2 and 4 to 5 , significant hysteresis exists in water vapor adsorption/desorption on both Berea sandstone and Monteverdi \#2 sample for the conditions investigated. The hysteresis persists to the very low pressure of the tests. The origin of the hysteresis is not yet clear to us.

It is interesting to note the rapid changes in the isothermal adsorption curves at higher relative pressures. This rapid increase in the amount of 


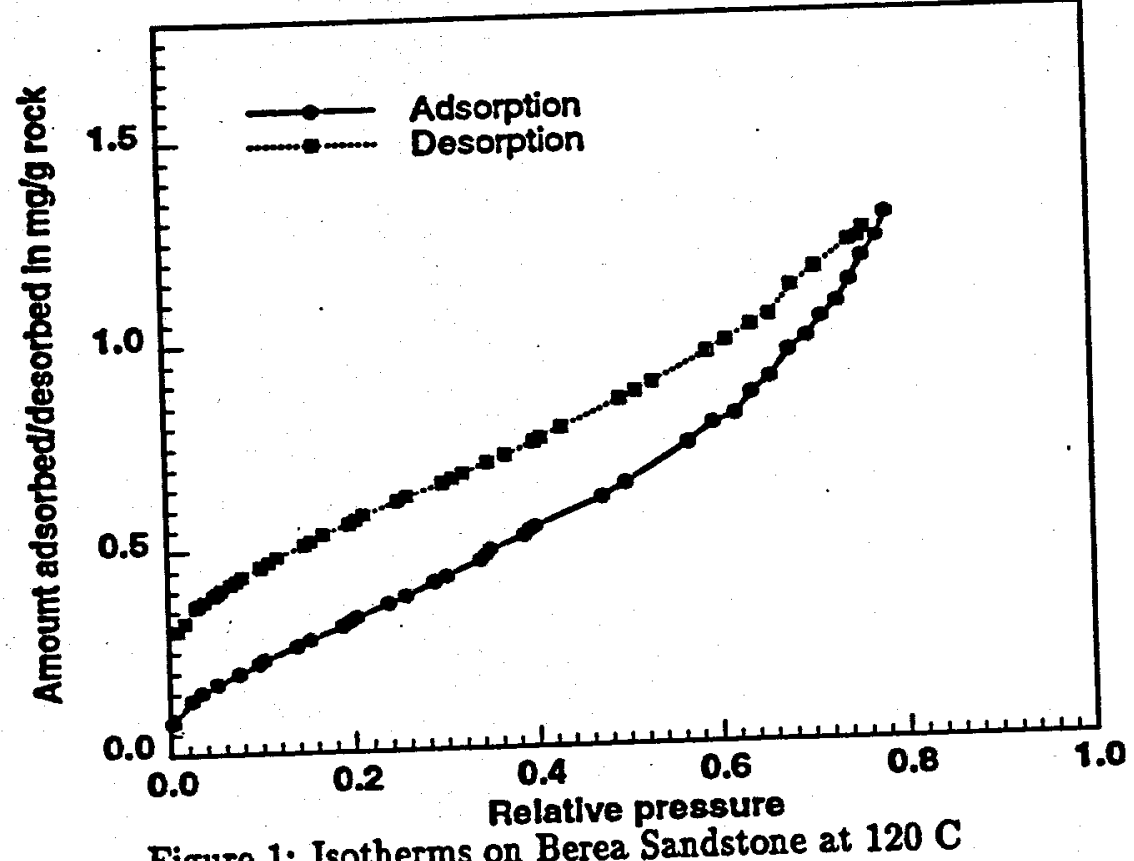

Figure 1: Isotherms on Berea Sandstone at $120 \mathrm{C}$

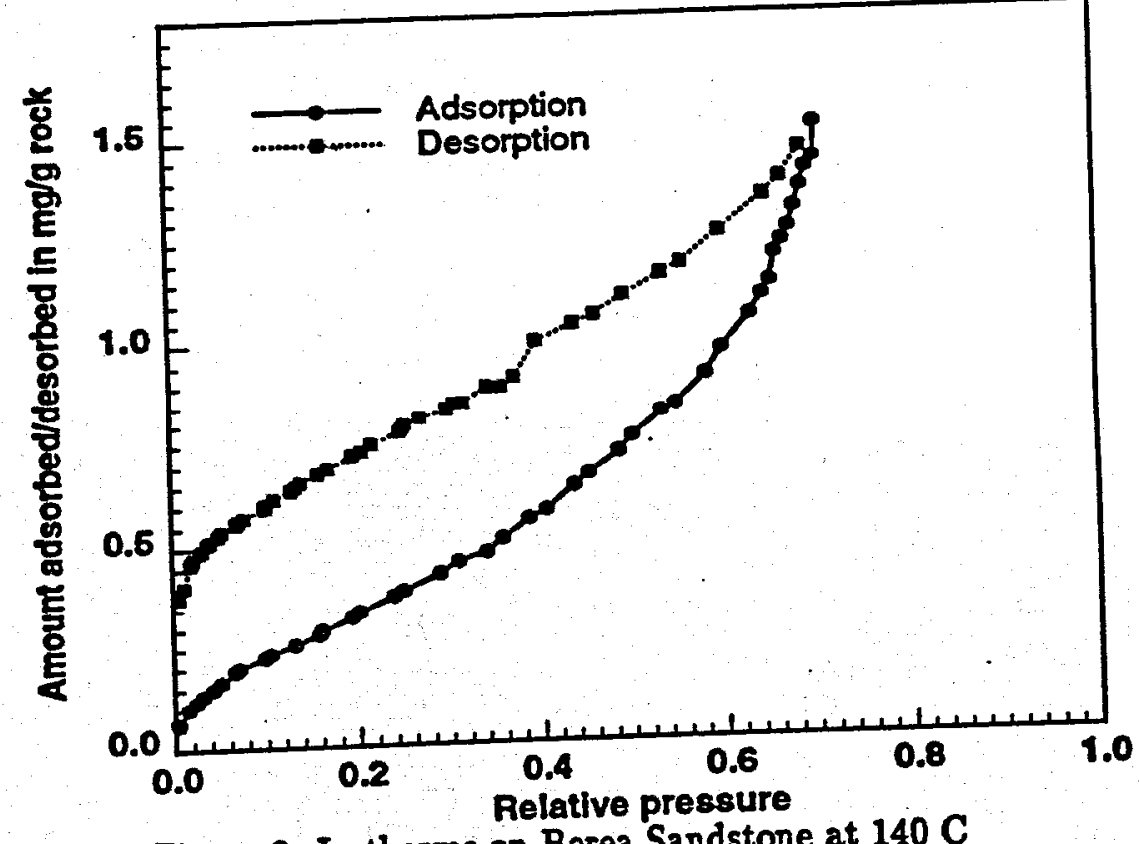

Figure 2: Isotherms on Berea Sandstone at $140 \mathrm{C}$ 


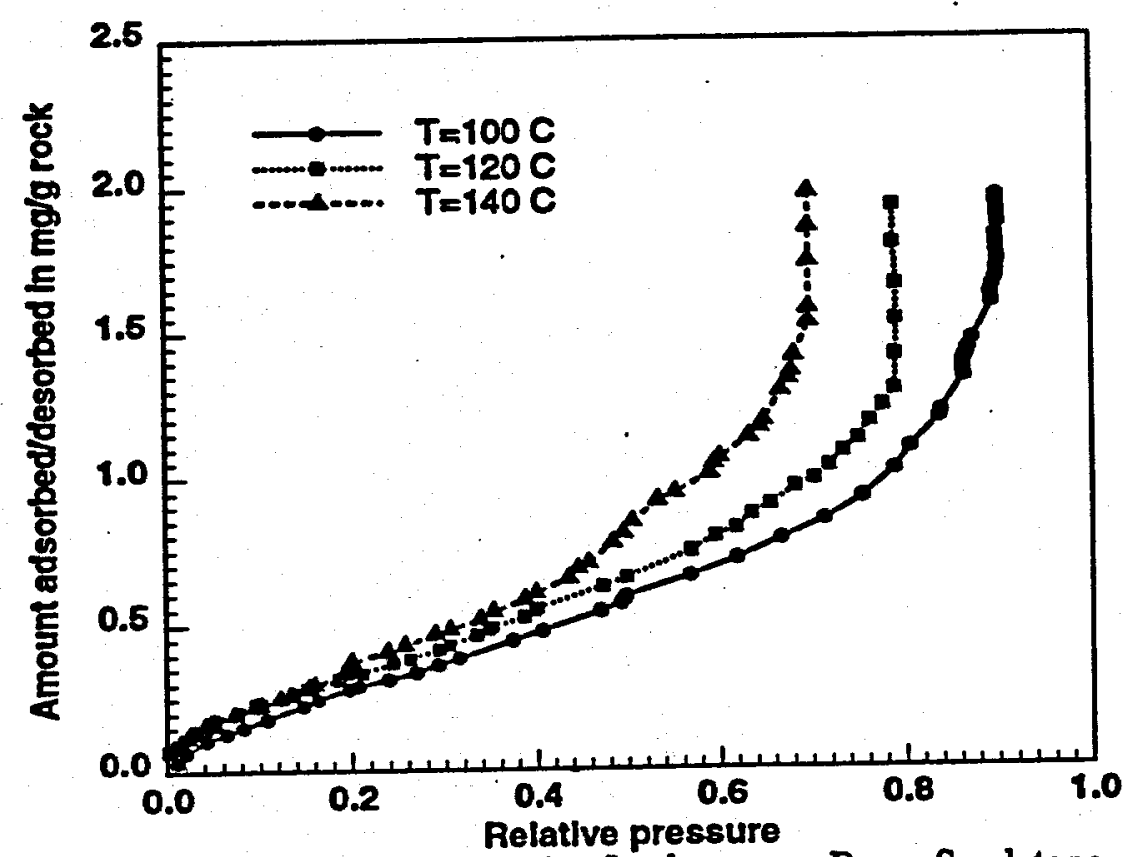

Figure 3: Comparison of Adsorption Isotherms on Berea Sandstone

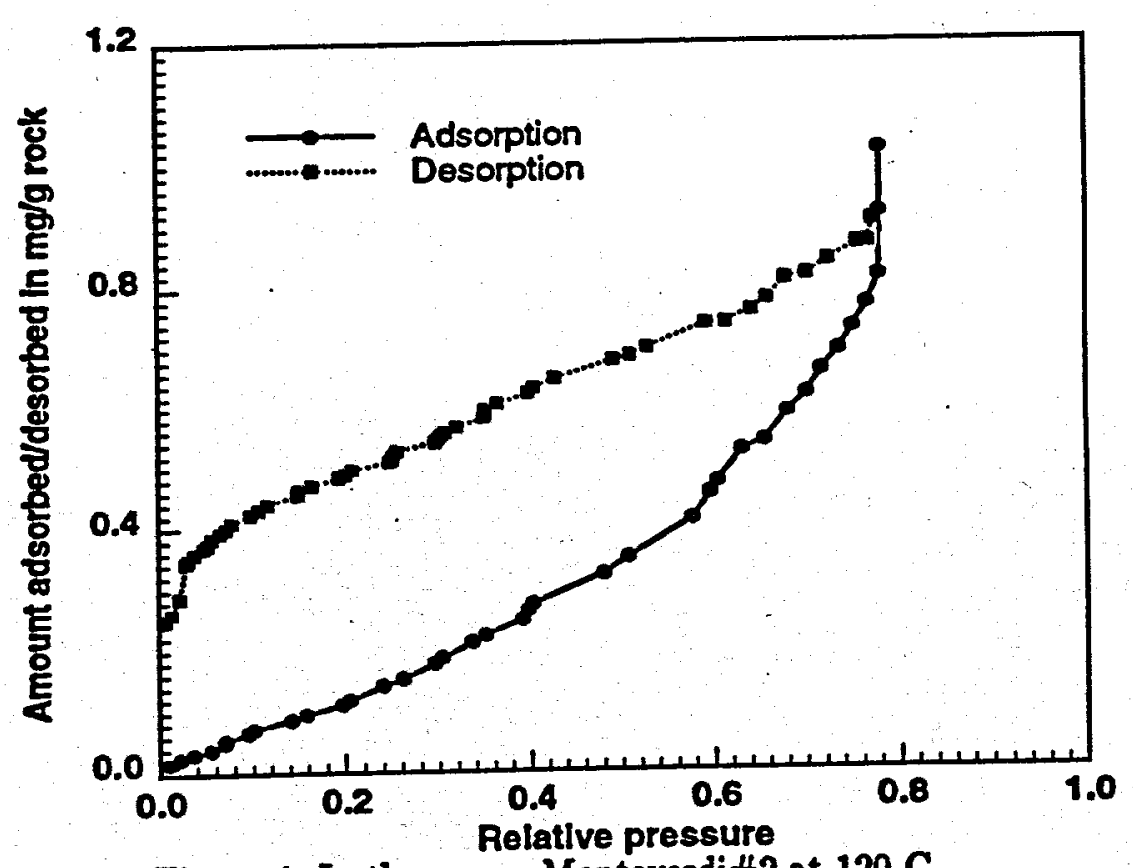

Figure 4: Isotherms on Monteverdi\#2 at $120 \mathrm{C}$ 


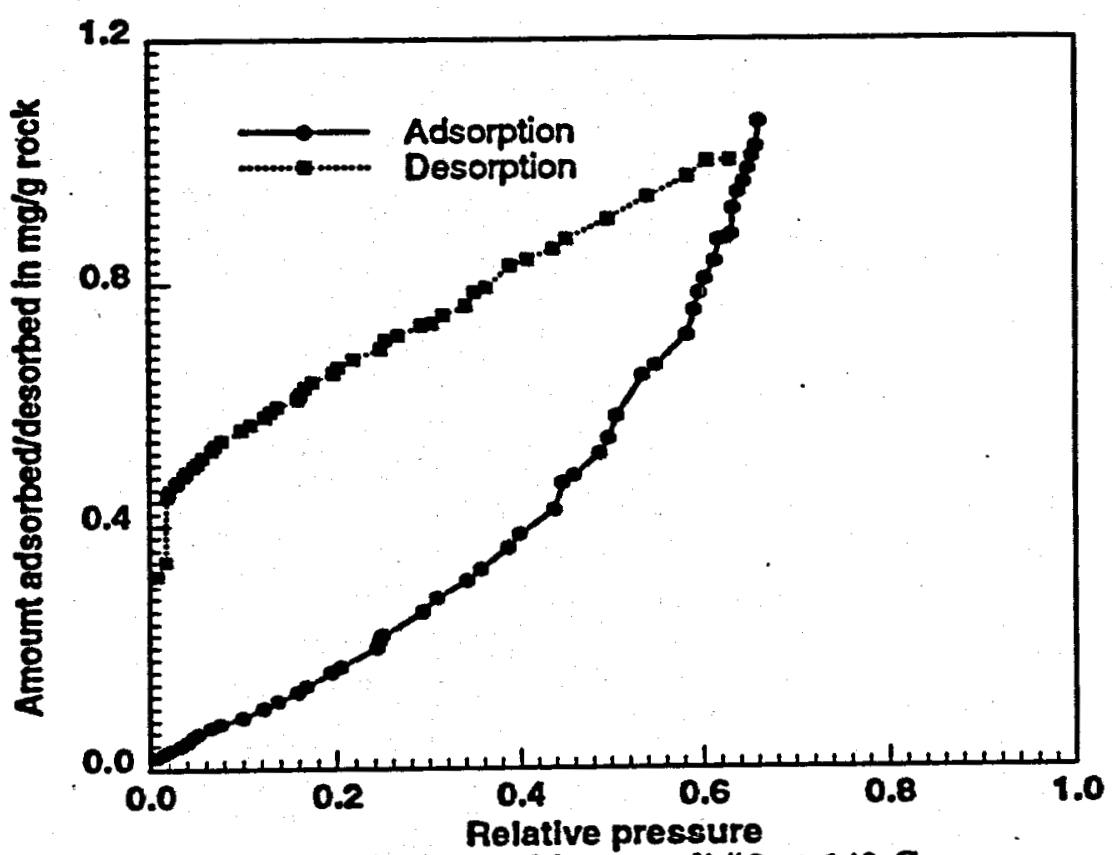

Figure 5: Isotherms on Monteverdi\#2 at $140 \mathrm{C}$

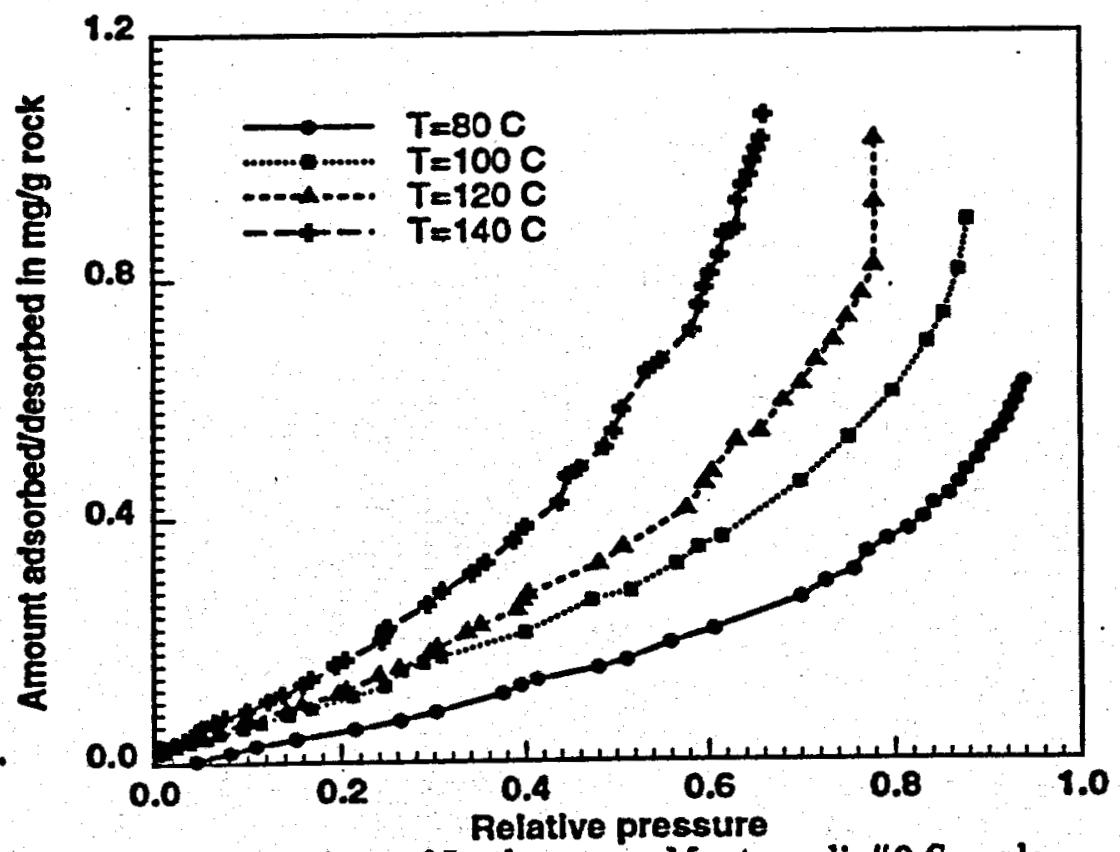

Figure 6: Comparison of Isotherms on Monteverdi \#2 Sample 
water retained indicates the occurence of capillary condensation. As shown in Figures 3 and 6, the relative pressure at which condensation occurs decreases with the increase in temperature. This observation emphasizes the importance of water vapor adsorption in geothermal systems. It should be noticed that the comparisons of the isotherms at different temperatures are made based on relative rather than absolute pressures. If the two sets of isotherms are plotted on absolute pressure basis, the trends are reversed. Thermodynamically, temperature and pressure have opposite effects on the amount of adsorption. There must be a crossover point beyond which the effect of pressure on adsorption is dominant. This explains the larger amount of water adsorbed at higher temperature, and consequently, the formation of an adsorbed film with given thickness at a lower relative pressure. The presence of the adsorbed water film not only changes the size of the pores in the reservoir rock, but also causes dissolution of minerals if they are present in the rock. With increase in temperature, the solubility of the minerals increases. Thus the dissolved salt concentration in the adsorbed film is likely to be higher at higher temperatures. The consequence of these effects is the occurence of water vapor condensation at pressures much lower than the corresponding saturation pressures, as observed in this study.

Currently, work is in progress to collect adsorption/desorption data on a range of reservoir samples. With the newly designed clamps, we expect to be able to run tests at temperatures higher than $140^{\circ} \mathrm{C}$ so that we can simulate reservoir temperature and pressure more closely. Continuous effort will be made on the development of a model to describe the adsorption-capillary condensation process.

\section{ESTIMATION OF ADSORPTION PARAM- ETERS FROM EXPERIMENTAL DATA}

This project is being performed by research assistant Ming Qi, together with Professors Roland N. Horne and Henry J. Ramey, Jr.. The purpose of the work is to obtain data for the estimation of adsorption isotherms, using a transient flow experiment.

\subsection{Introduction}

As discussed in the previous quarterly report, there were only four sets of vapor pressure transient data available. So the work of the last three 
months was focused on running more pressure transient tests for analysis. Eight more set of data were obtained during the summer. The equipment used was built by Herkelrath et al. (1983) at the U.S.G.S.. It is the same equipment that Harr (1991) used to obtain the four sets of transient test data.

\subsection{Experiment Equipment Modification}

The data acquisition system used in the transient test equipment was an old fashioned Digital RX02 computer with a VT105 monitor. The pressure transient data were first recorded on a 8 inch soft diskette. Then the diskette must be taken to the U.S.G.S. to get the data transfered from the diskette onto an IBM-PC diskette for further use. This is very inconvenient. During the summer, we successfully replaced the terminal with an IBM-PC computer so that now the pressure transient data can be seen and saved directly onto the IBM-PC.

\subsection{Pressure Transient Experiment Results}

To data, eight runs have been made. The eight samples used for the experiment were:

- Geysers Shallow Reservoir - Unknown Well, depth 5000' - 5200', sample size: 28 - 150 mesh;

- Geysers OF52-11 Well at the depth between 5000' - 5200', sample size: 10 - 150 mesh;

- Geysers OF52-11 Well at the depth between 5000' - 5200', sample size: 20 - 150 mesh;

- Geysers OF52-11 Well at the depth between 8000' - 8200', sample size: 30 - 80 mesh;

- Geysers OF52-11 Well at the depth between 8000' - 8200', sample size: 30 - 150 mesh;

- Monteverdi 2, Italy, sample size: 10 - 150 mesh;

- Reykjanes Well 9, Iceland, drill cuttings at 1000 meter depth, sample size: 10 - 150 mesh; 
- Unocal Well Megu-15 ST2 at the depth between 8600' - 8800', sample size: 20 - 150 mesh;

All runs are under the same conditions that Harr (1991) used so that we could compare some of our data for the purpose of checking and analysing. No higher temperatures were used in the fear that excessive heating would cause the o-rings in the pnepmatic valves located inside the oven to acquire a permanent set and thus cause the leakage problems as commented in Harr (1991). The eight experiment results are shown in Figure 7 to Figure 14.

\subsection{Discussion}

All results showed more or less similar pressure decline curves on a semilog plot. There are pressure differences between some of our results and Harr's results. As shown in Figures 8 and 11, the starting relative pressures are much lower than that of Harr's results. This was probably caused by using different sample holders in case of Figure 8. Two sample holders were used by Harr: one is $\mathbf{2 . 3 6 2}$ centimeters in diameter and $\mathbf{3 1 . 7}$ centimeters in length and another is 1.727 centimeters in diameter and 30.63 centimeters in length. There is a short tube connecting sample holder and pressure transducer with a valve in between. Every time we measured the steam pressure, we evacuated the tube first and then opened the valve. Thus part of steam flowed from sample into this short empty tube. This lowered the steam pressure inside the sample holder. When the large sample holder was used (Harr's case) this effect was not significant, but for the small sample holder, the space inside the empty tube was relatively large compared with the space inside the sample itself. When the valve opened, a relatively large amount of steam flowed out of the sample to fill the empty space and the pressure drop was more severe than in the large sample holder case. This resulted in the relative pressure difference because the saturated vapor pressures were the same. Figure 7 shows another pair of results. The two results were more comparible because the same sample holder was used. As for the case in Figure 11, the difference was caused by the measuring error. The data in Harr's report (1991) showed the pressures of atmosphere recorded after the run were 1.2365 bars at top of the sample holder and 0.6022 bars at the bottom of the sample holder. It was impossible to have such kind of atmosphere pressures. 


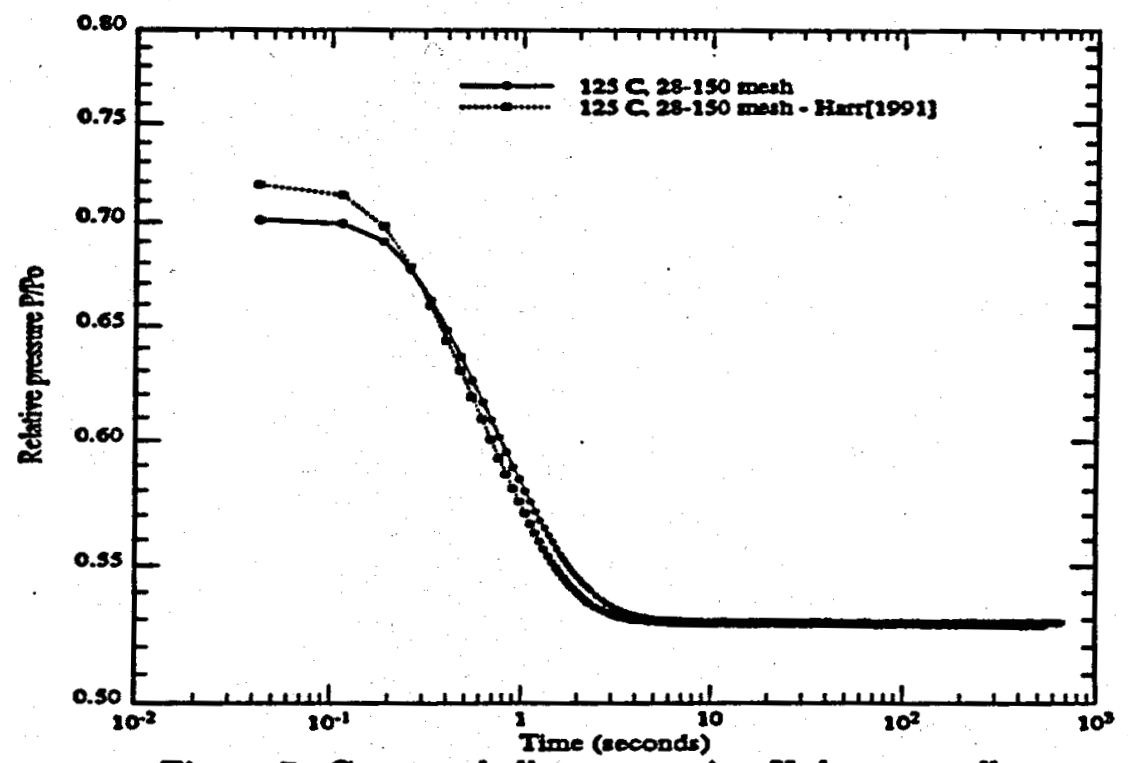

Figure 7: Geysers shallow reservoir - Unknown well

\subsection{Future Work}

By running the one-dimensional steam flow simulator developed by Nghiem and Ramey (1991) combined with nonlinear regression technique, we can estimate the adsorption isotherm parameters from pressure transient data. This was partly done by using Harr's experimental results. The new experimental data will be used to further test and improve the parameter estimation technique. More experimental work will also be done as the research continues.

\section{HEAT OF DESORPTION AND RESERVOIR BEHAVIOR}

This work is being undertaken by research assistant Richard Holt, together with Profs. Roland N. Horne and Henry J. Ramey, Jr. The objective is to investigate the effects of adsorption on heat transfer. 


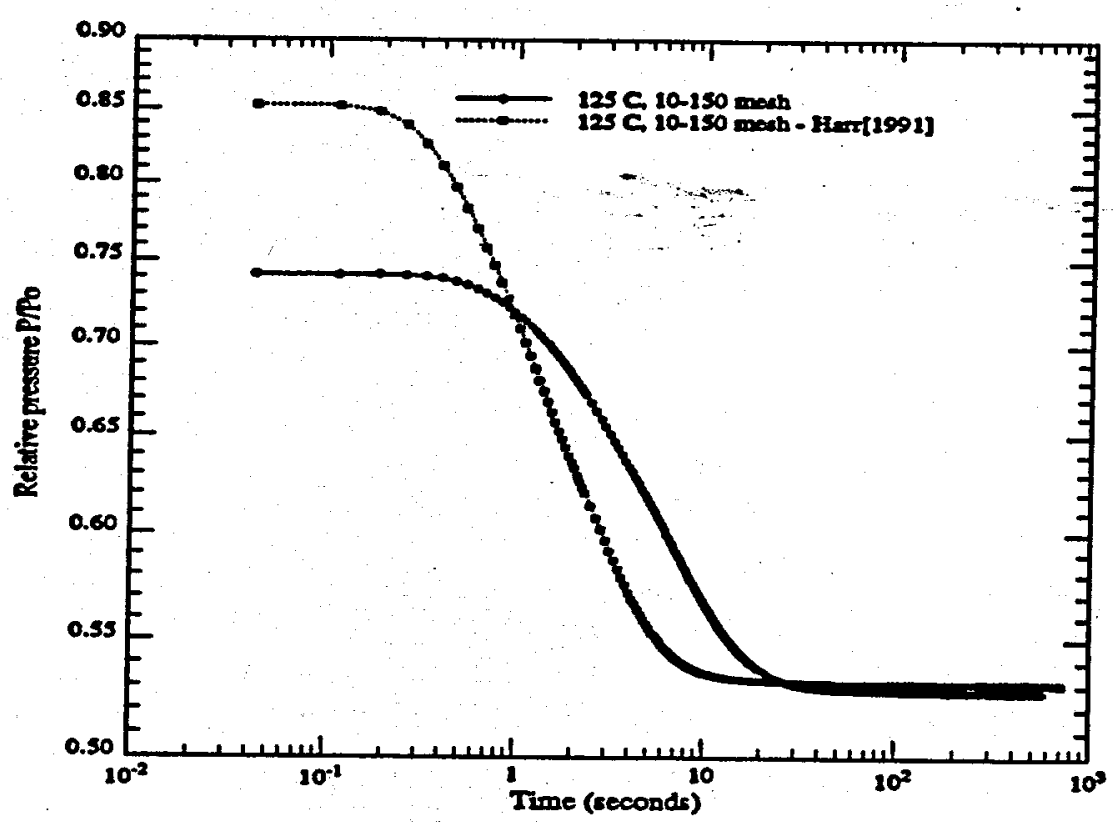

Figure 8: Geysers well OF52-11

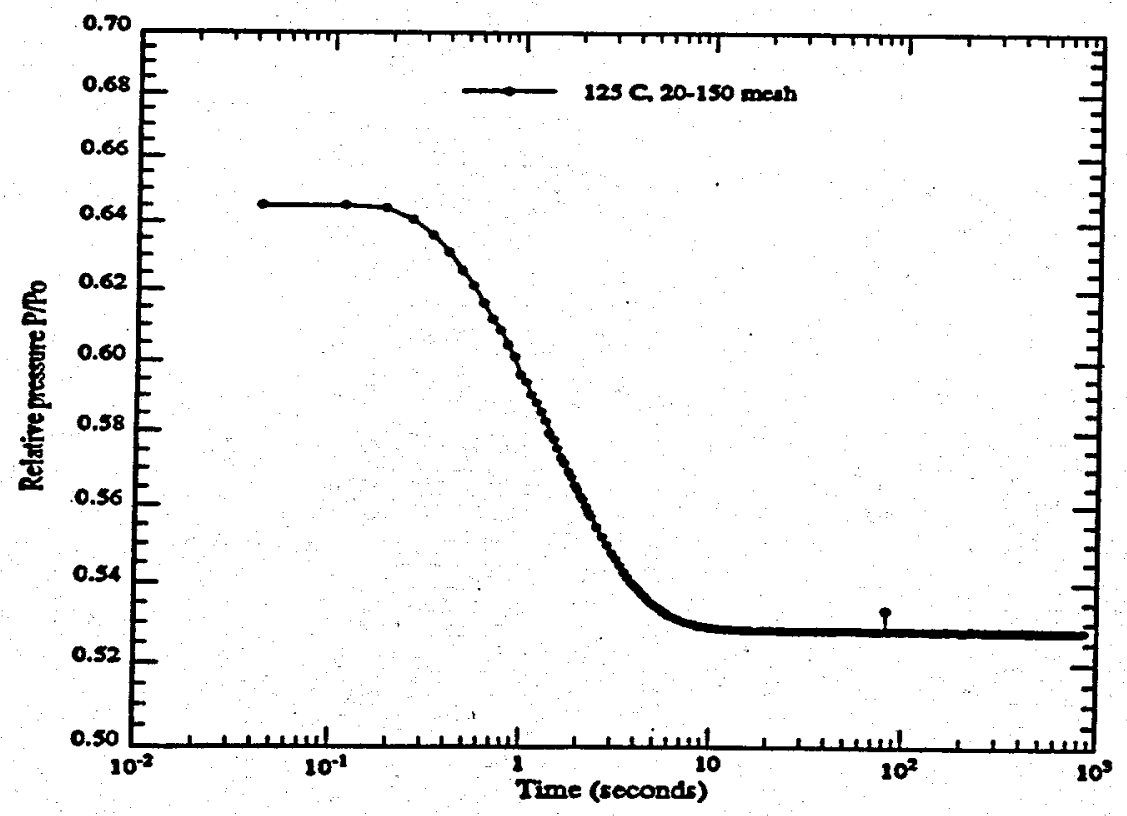

Figure 9: Geysers well OF52-11 


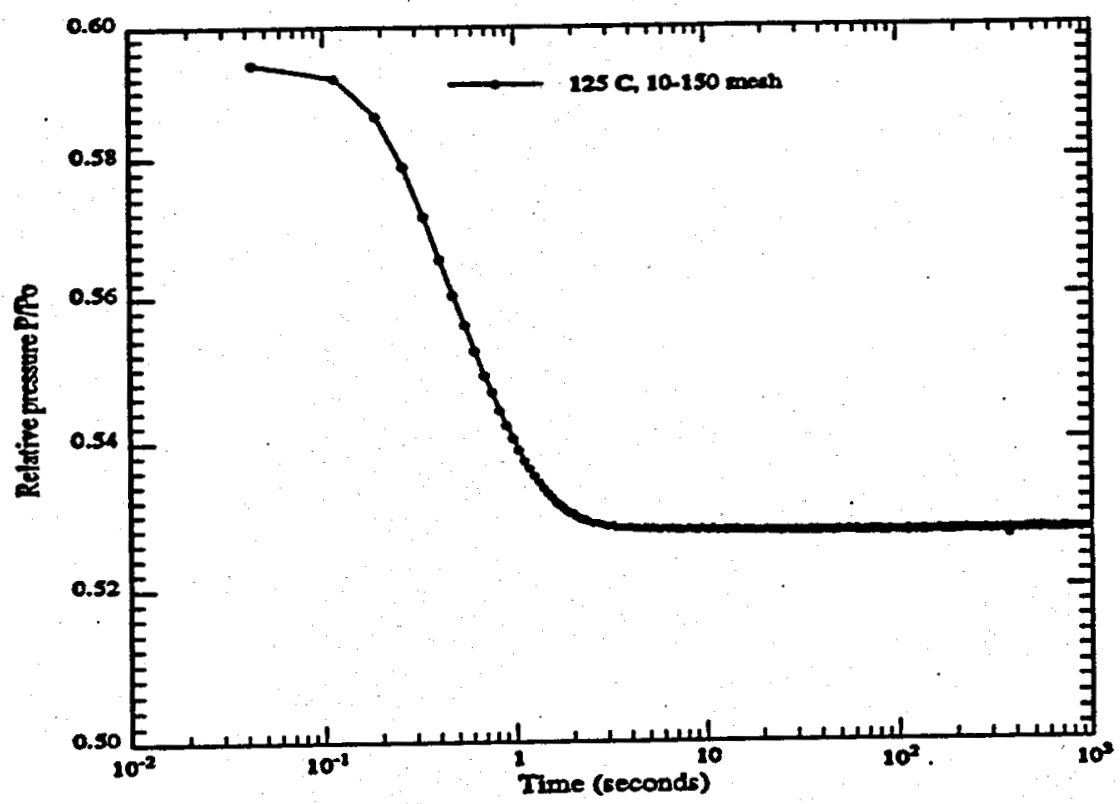

Figure 10: Well Monteverdi 2, Italy

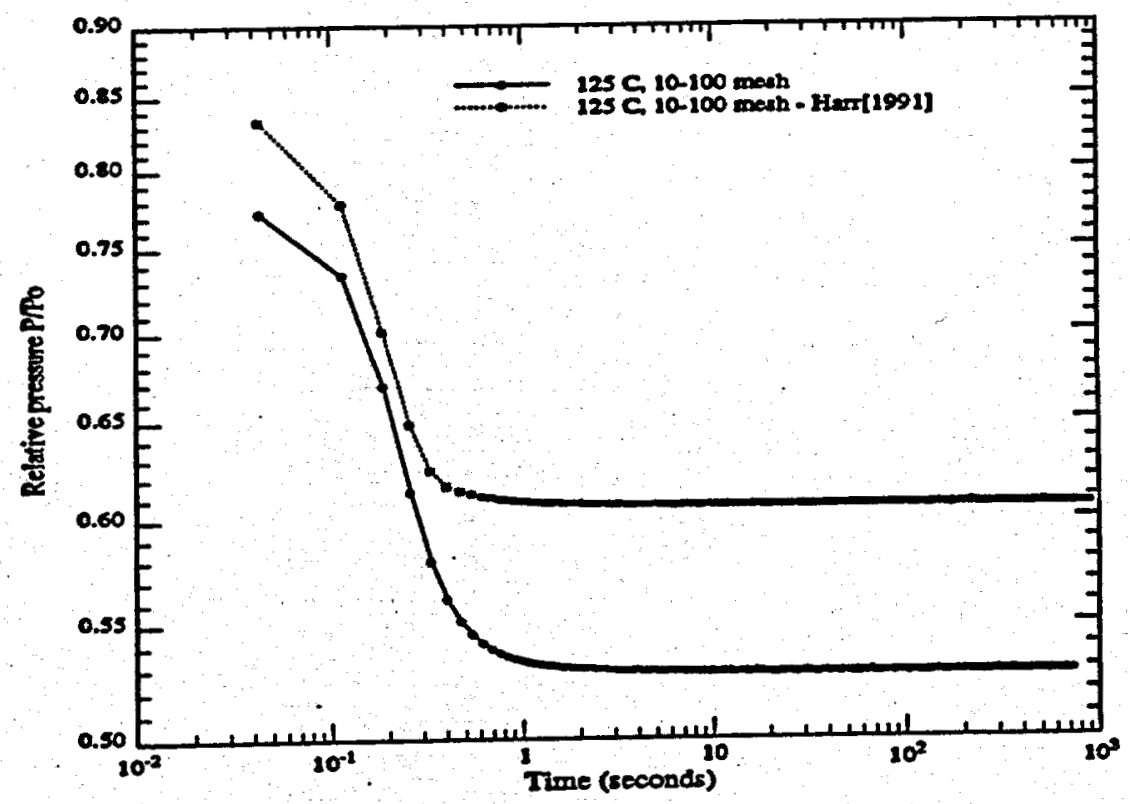

Figure 11: Reykjanes well 9, Iceland 


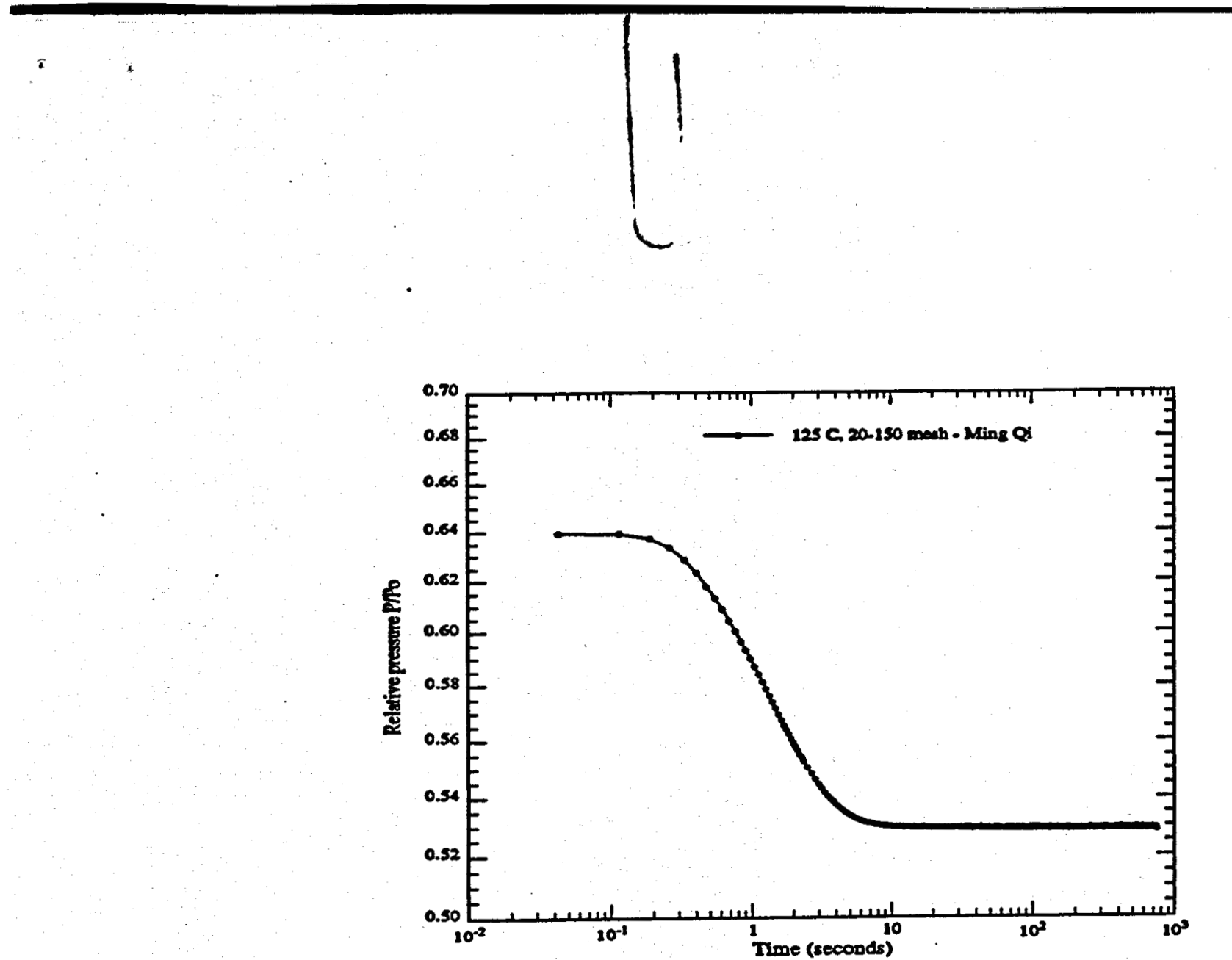

Figure 12: UNOCAL well MEGU-15 ST2

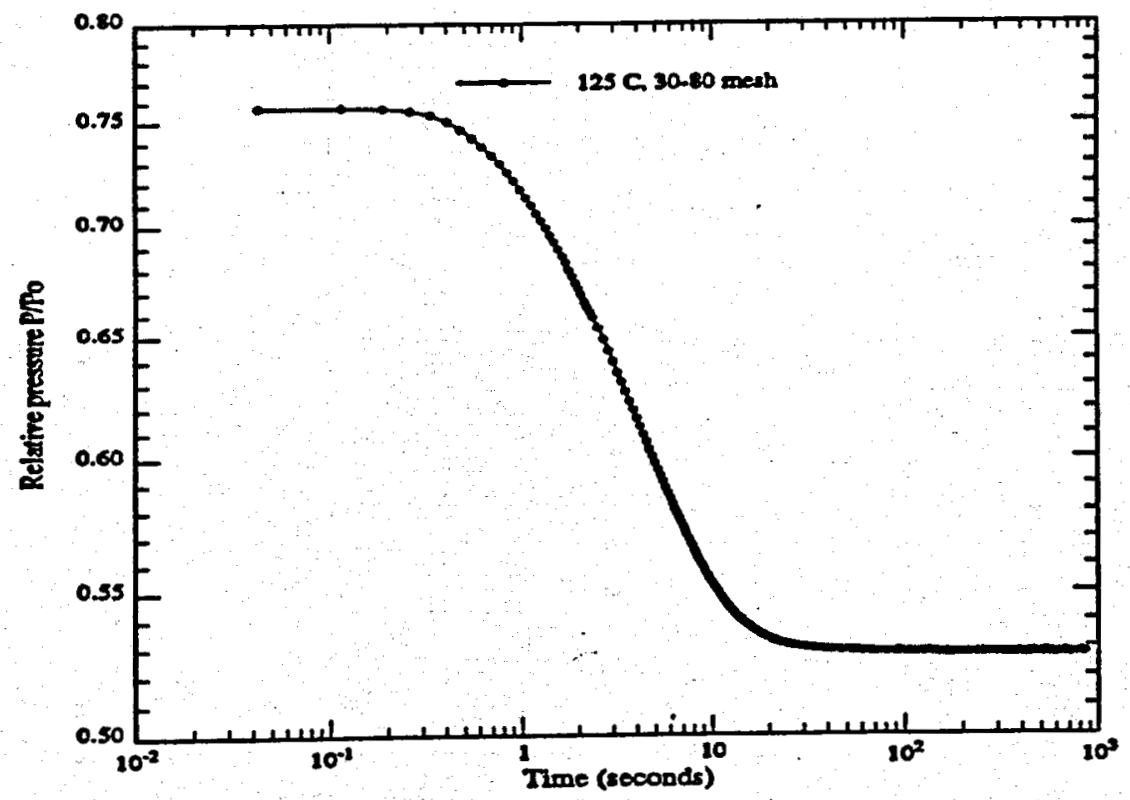

Figure 13: UNOCAL well MEGU-15 ST2 


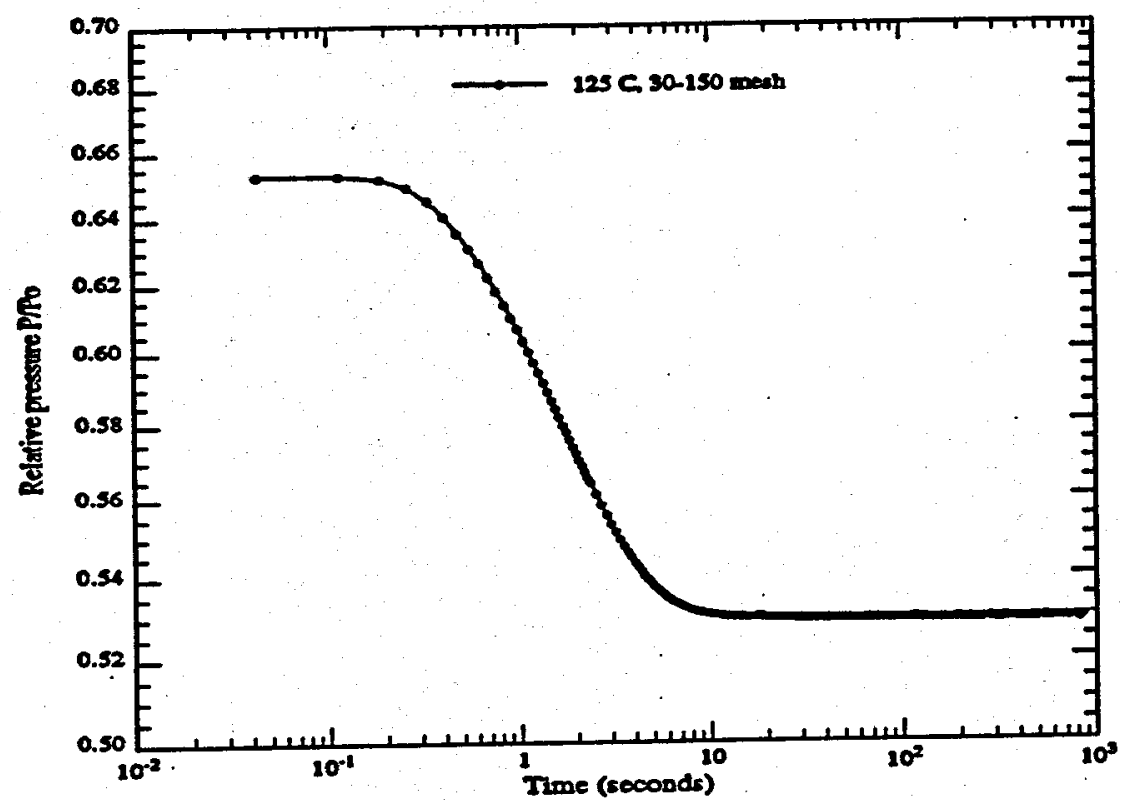

Figure 14: Geysers well OF52-11

\section{3.i Introduction}

Much of the analytical and numerical modeling of desorbing geothermal systems has been performed under the isothermal assumption. That is, the heat of desorption is assumed small, so large gradients in temperature are not expected. If the heat of desorption is large, however, then the isothermal assumption is less valid. Unfortunately, the heat of desorption of water from geologic material is not exactly known. The heat of desorption is one experimental result which may be determined during our experimental project on adsorption (see Section 1).

\subsection{One Block Model}

In anticipation of learning more about the heat of desorption, the following study was made. A one block reservoir model was developed to explore the possible effects of the heat of desorption on overall reservoir performance. Equation 1 is an material and energy balance on a block of porous media with a vaporizing liquid phase. The left side is the heat required to vaporize an amount of liquid from the water, rock, and steam system. The right side 
is the heat required to change the temperature of the water, rock, and steam system. Temperature dependences of thermal properties were modeled using correlations (Ejiogu, 1987). In Equation 1, as the water phase evaporates, the heat lost through the heat of evaporation is balanced by an appropriate reduction in temperature in the system.

$$
\rho_{w} H \Delta S_{w}=\left[(1-\phi) C_{p r} \rho_{r}+S_{w} C_{p w} \phi \rho_{w}+\left(1-S_{w}\right) C_{p s} \phi \rho_{s}\right] \Delta T
$$

To study the pressure - temperature behavior for different heats of desorption the following procedure was taken. A small change in water saturation was inserted into Equation 1. Using Equation 1, the change in temperature is calculated. With the new temperature, vapor pressure is then calculated. For the case of no adsorption, vapor pressure at a temperature was found in a standard steam table. That is, vapor pressure is a function of temperature only, in the absence of adsorption. For situations with adsorption, vapor pressure is a function of both liquid saturation and temperature. For the cases with adsorption, vapor pressure was estimated by multiplying steam table vapor pressure by a reduction factor based on the Langmuir isotherm. The process was repeated for different values of heat of desorption, $H$. The desorbing runs are compared to a run which did not include desorption. For the run with no adsorption, heat of evaporation for flat surface was used.

Figure 15 compares the behavior of a reservoir with flat surface thermodynamics to a desorbing system with various heats of desorption. Note that as the heat of desorption becomes large, the desorbing system approaches the behavior of the flat surface system with respect to pressure and temperature. For small heats of desorption, the pressure drops almost isothermally, as expected.

Figure 16 compares the pressure - saturation behavior of a system with flat surface thermodynamics to desorbing systems with various heats of desorption. Note that for large and small heats of desorption, vapor pressure is much lower in the desorbing systems at each level of saturation. Figure 16 models the pressure behavior as a reservoir is depleted. That is, the change in water saturation can be related to amount of steam produced. Therefore, if adsorption is occurring, reductions in vapor pressure can be expected as a field is depleted, regardless of the heat of desorption. 


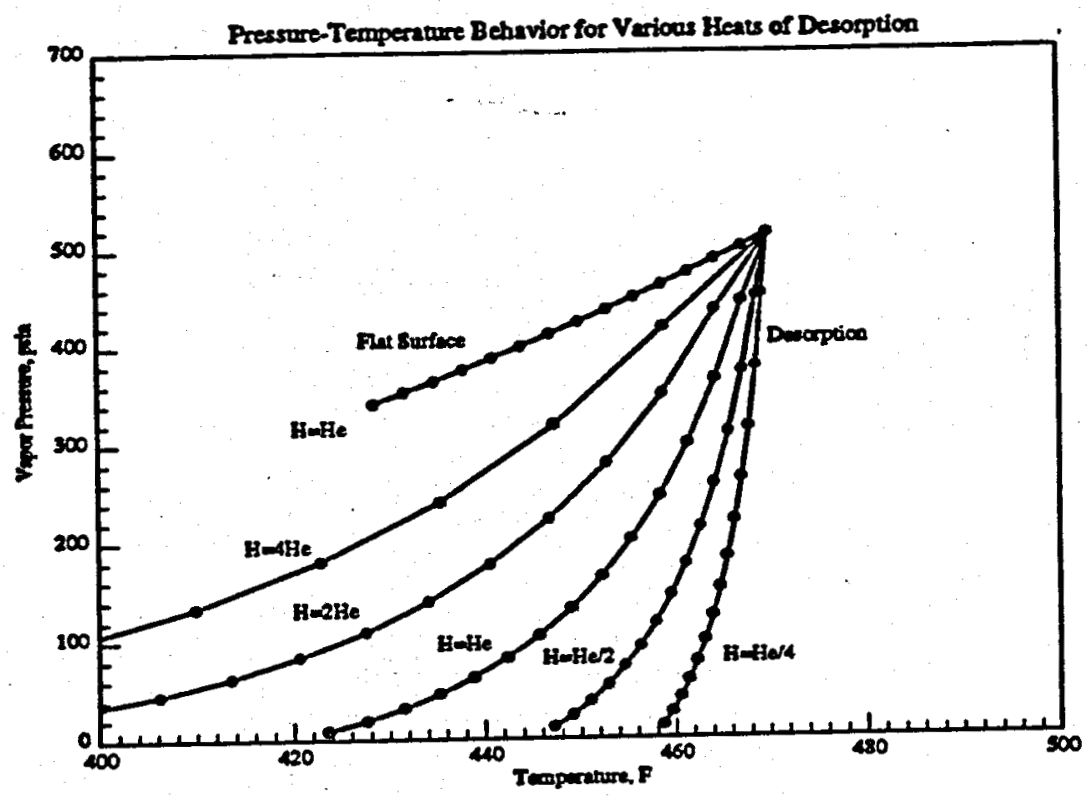

Figure 15: Adsorption/Desorption Isotherms at $80 \mathrm{C}$

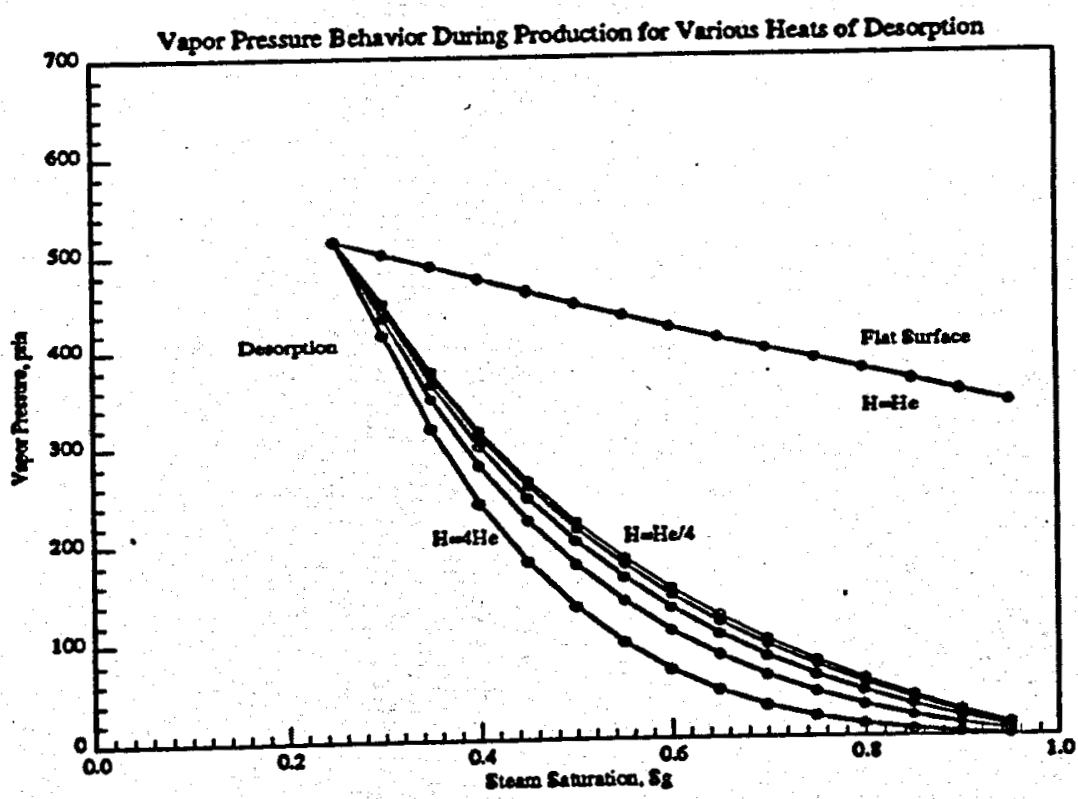

Figure 16: Adsorption/Desorption Isotherms at $80 \mathrm{C}$ 


\subsection{Nomenclature}

$\begin{aligned} \phi & =\text { bulk rock porosity } \\ S_{w} & =\text { water saturation } \\ S_{g} & =\text { gas saturation } \\ C_{p s} & =\text { specific heat of steam } \\ C_{p s} & =\text { specific heat of steam } \\ C_{p r} & =\text { specific heat of rock } \\ C_{p w} & =\text { specific heat of wates } \\ H_{e} & =\text { heat of evaporation for water } \\ H & =\text { total heat of desorption for water } \\ \rho_{s} & =\text { density of steam } \\ \rho_{r} & =\text { density of rock } \\ \rho_{w} & =\text { density of water }\end{aligned}$

\section{PHYSICS OF INJECTION INTO VAPOR- DOMINATED RESERVOIRS}

This project is under the direction of research assistant John W. Hornbrook and Professor Roland N. Horne. The goal of this work is to understand the physics of fluid storage and transport in geothermal reservoirs with adsorption effects present. In particular, this research is aimed at determining whether or not adsorption significantly affects the transport of fluid and heat in geothermal reservoirs.

\subsection{Introduction}

As in oil and gas reservoirs, the fluids in geothermal reservoirs are depletable. The difference between depletion of petroleum and geothermal reservoirs is that the energy is usually not depleted from geothermal reservoirs even when all the fluid is gone. The energy stored in geothermal reservoirs is in the form of heat, and, due to the high heat capacity and total mass of reservoir rocks, most of the heat stored in a geothermal reservoir cannot be removed under primary production. It is common, therefore, to inject produced water into geothermal reservoirs to increase the productive life of the reservoir and to maximize the extraction of heat from the reservoir.

In order to design effective injection and production programs for geothermal reservoirs, the physics of the flow in the reservoirs must be understood. However, understanding this flow is not an easy task. Geothermal reser- 
voirs are, in general, highly fractured and heterogeneous, and the transport of fluids is influenced strongly by heat diffusion and, possibly, by adsorption or capillary retention effects.

The first stage in understanding the physics of flow in geothermal reservoirs is understanding the isothermal flow of fluids in porous and fractured media. The petroleum engineering literature is replete with analyses of isothermal flow in porous and fractured media and a list of references applicable to geothermal reservoirs would be extremely cumbersome if not impossible. It is left to the interested reader to survey this extensive literature to obtain adequate background material.

The second stage in understanding geothermal systems is understanding the simultaneous transport of fluid and heat in porous media. Several researchers have carried out research in this area. Crank (1964) presented a mathematical analysis of the simultaneous diffusion of pressure and heat. Herkelrath, et. al. (1983) and Moench and Atkinson (1978) presented models for the simultaneous diffusion of fluid and heat in one dimensional systems and matched experimental data. Pruess et. al. (1987) presented an analytical solution for heat transfer at a boiling front, while Fitzgerald and Woods (1992a), Fitzgerald and Woods (1992b), Woods and Fitzgerald (1992), and Doughty and Pruess (1992) presented similarity solutions describing the flow of liquid, vapor, and heat in geothermal reservoirs.

Despite the extensive background in the flow of fiuids and heat in porous media described above, a third stage is necessary to understand fluid flow in geothermal systems. Research by Calhoun et. al. (1949), Udell (1982), and Hsieh and Ramey (1983) among others, indicates that adsorption and/or capillary condensation may play a significant role in determining the flow and storage characteristics in geothermal reservoirs. Additionally, the fractured nature of many geothermal reservoirs highlights the importance of studying flow in fractured media. The third stage, then, in understanding fluid flow in geothermal reservoirs is to incorporate adsorption effects and fracture flow effects into the current geothermal flow models.

The following analysis describes the injection of water into, the generation of vapor within, and the production of vapor from a fractured geothermal reservoir with adsorption effects included.

\subsection{Derivation of the Fundamental Flow Equation}

The analysis carried out here represents an attempt to fully describe the flow of fluids in a geothermal reservoir under a wide range of conditions. 
The analyses of Woods and Fitzgerald (1992) have been extended to include flow in fractures and the effects of adsorption. The following assumptions have been made:

1. Matrix rock is of constant, low porosity $(\phi<1)$.

2. Fracture porosity is large $(\phi \approx 1)$.

3. Darcy's law is valid for flow through porous media.

4. Adsorbate phase is immobile.

5. Adsorption isotherm may be approximated by a linear relationship. While this assumption can lead to large errors at intermediate pressures, it allows a general description of adsorption effects. This assumption will be relaxed later in the course of this research when a more complete set of adsorption isotherms is measured in our experimental project described in Section 1 of this report.

The conservation of mass is expressed as:

$$
\phi \frac{\partial \dot{\rho}_{l}\left(1-S_{a}\right)}{\partial t}+\phi \rho_{a} \frac{\partial S_{a}}{\partial t}+\nabla\left(u_{l} \cdot \nabla \rho_{l}\right)=0
$$

The above equation includes two advection terms. The first describes the motion of the free liquid phase, whether this be liquid or vapor, while the second describes the motion of the adsorbate phase. Since adsorbate is assumed to have no flow velocity, the third term involves only free liquid. Upon rearrangement, Eqn. (2) becomes:

$$
\phi \frac{\partial\left(\rho_{l}-\rho_{l} S_{a}\right)}{\partial t}+\phi \rho_{a} \frac{\partial S_{a}}{\partial t}+\nabla\left(u_{l} \cdot \nabla \rho_{l}\right)=0
$$

The adsorbate saturation is pressure dependent and is described by an adsorption isotherm:

$$
S_{a}=\frac{1-\phi}{\phi} \frac{\rho_{r}}{\rho_{a}} X(p)
$$

Upon substitution of Eqn. (4) into Eqn. (3) and simplifying:

$$
\left[1-\left(\frac{1-\phi}{\phi}\right) \frac{\rho_{r}}{\rho_{a}} X\right] \frac{\partial \rho_{l}}{\partial t}+\left[\left(\frac{1-\phi}{\phi}\right) \rho_{r}-\left(\frac{1-\phi}{\phi}\right) \frac{\rho_{r} \rho_{l}}{\rho_{a}}\right] \frac{\partial X}{\partial t}+\frac{1}{\phi} \nabla\left(u_{l} \cdot \nabla \rho_{l}\right)=0
$$


Eqn. (5) may be simplified further by observing:

$$
\frac{\partial X}{\partial t}=\frac{\partial \rho_{l}}{\partial t} \frac{\partial X}{\partial \rho_{l}}
$$

Substitution of Eqn. (6) into Eqn. (5) yields:

$$
\left[\left\{1-\left(\frac{1-\phi}{\phi}\right) \frac{\rho_{r}}{\rho_{a}} X\right\}+\left\{\frac{\partial X}{\partial \rho_{l}}\left(\left(\frac{1-\phi}{\phi}\right) \rho_{r}-\left(\frac{1-\phi}{\phi}\right) \frac{\rho_{r} \rho_{l}}{\rho_{a}}\right)\right\}\right] \frac{\partial \rho_{l}}{\partial t}+\frac{1}{\phi} \nabla\left(u_{l} \cdot \nabla \rho_{l}\right)=0
$$

Fluid velocity is obtained from Darcy's law:

$$
u_{l}=-\frac{k}{\mu_{l}} \nabla p
$$

Upon substitution of Eqn. (8) into Eqn. (7):

$$
A(p) \frac{\partial \rho_{l}}{\partial t}+\frac{1}{\phi} \nabla\left(-\frac{k}{\mu_{l}} \nabla p \cdot \nabla \rho_{l}\right)=0
$$

where the nonlinear term, $A(p)$, is given by:

$$
A(p)=\left\{1-\left(\frac{1-\phi}{\phi}\right) \frac{\rho_{r}}{\rho_{a}} X\right\}+\left\{\frac{\partial X}{\partial \rho_{l}}\left(\left(\frac{1-\phi}{\phi}\right) \rho_{r}-\left(\frac{1-\phi}{\phi}\right) \frac{\rho_{r} \rho_{l}}{\rho_{a}}\right)\right\}
$$

Pressure and density of the vapor are related by the real gas law:

$$
p=\rho_{l} R_{g} T z
$$

Substitution of Eqn. (11) into Eqn. (9) holding vapor viscosity and permeability constant over $x$ we can obtain an expression for the advection and dispersion of vapor in porous media with adsorption effects included:

$$
\frac{\partial p}{\partial t}=\frac{k}{\phi A(p) \mu l} \nabla \cdot(p \nabla p)
$$

Eqn. (12) describes the nonlinear diffusion of pressure in a porous medium. The nonlinearity is borne by the nonlinear $A(p)$ term and the magnitude of this term determines the effects of adsorption on fiuid transport: 
1. If $A=1$, there are no adsorption effects. Much research has been carried out on flow in homogeneous porous media under these conditions, Woods and Fitzgerald (1992), Pruess and O'Sullivan (1992), Pruess, et. al. (1987).

2. If $A<1$, pressure diffusion is increased relative to a system with no adsorption effects.

3. If $A>1$, pressure diffusion decreases relative to system with no adsorption effects.

\subsection{If $A$ is Nonunity - Adsorption effects present}

If the nonlinear term (A) is nonunity, then adsorption effects play a role in the flow and storage of fluids in geothermal reservoirs. In order to understand this flow, analyses similar to those carried out for flow without adsorption must be undertaken. A five step plan is being followed to fully characterize geothermal systems:

1. Characterization of the nonlinear term. The nonlinear term must be fully understood for a range of geothermal systems. Understanding this term depends to a large extent upon the understanding of the process of adsorption (see Section 1 of this report).

2. Modeling of the heat transfer mechanism. It is necessary to understand how the process of adsorption affects heat transfer between reservoir rock and fluid. This understanding must them be applied to analytical model for heat flow in conjunction with fluid flow.

3. Investigation of relative rates of fluid and heat transport. An investigation similar to that of Woods and Fitzgerald (1992) must be carried out on a system which includes adsorption effects to determine basic flow characteristics.

4. Investigation of the influence of fractures on fluid flow. The flow of fluid and heat in fractures (high porosity) must be investigated to determine if results from porous media may be easily extended to fractured media.

5. Solution of an analytical expression for fluid and heat flow in porous media with adsorption effects included. This solution is to be written 
as a perturbation expansion 80 the effects of adsorption may be easily separated from convective and diffusive effects.

\subsection{Characterization of the Nonlinear Term}

In order to understand the advection and diffusion of fluids with adsorption effects present, the nonlinear diffusion coefficient must be fully understood so it may be modelled properly. The nonlinear flow term is given by:

$$
A(p)=\left\{1-\left(\frac{1-\phi}{\phi}\right) \frac{\rho_{r}}{\rho_{a}} X\right\}+\left\{\frac{\partial X}{\partial \rho_{l}}\left(\left(\frac{1-\phi}{\phi}\right) \rho_{r}-\left(\frac{1-\phi}{\phi}\right) \frac{\rho_{r} \rho_{l}}{\rho_{a}}\right)\right\}
$$

An in-depth analysis of the nonlinear term reveals where nonlinearities arise and the magnitude of these nonlinearities. Constants in the nonlinear term are: porosity $(\phi)$, rock density $\left(\rho_{r}\right)$, and adsorbate density $\left(\rho_{a}\right)$. Liquid density $\left(\rho_{l}\right)$ may or may not be pressure dependent, while adsorbed mass $(X)$ is strongly dependent on pressure. If liquid density represents water, the density is not pressure dependent. If the liquid density represents vapor, however, the density is a function of pressure.

Constants were assigned values consistent with data taken from the Geysers reservoir. These values are as follows:

1. Porosity $(\phi)=5.0 \%$.

2. Rock density $\left(\rho_{r}\right)=2.65 \mathrm{~g} / \mathrm{cc}$.

3. Adsorbate density $\left(\rho_{a}\right)=1.00 \mathrm{~g} / \mathrm{cc}$.

4. Water density $\left(\rho_{l}\right)=1.00 \mathrm{~g} / \mathrm{cc}$.

Vapor density is a function of both pressure and temperature. Assuming relatively small temperature changes, the pressure dependency of vapor density is obtained from a standard steam table. Figure 17 illustrates vapor density over a range of pressures.

Data on adsorbed mass are more difficult to obtain than vapor density and are less reliable. Several attempts have been made to quantify adsorption in the Geysers reservoir. A linear isotherm was selected to represent the adsorption isotherm Figure 18. Endpoint adsorption values correspond to endpoint values on actual nonlinear isotherms. A plot of the resulting nonlinear term for vapor over a range of relative pressures is shown in Figure 19. 


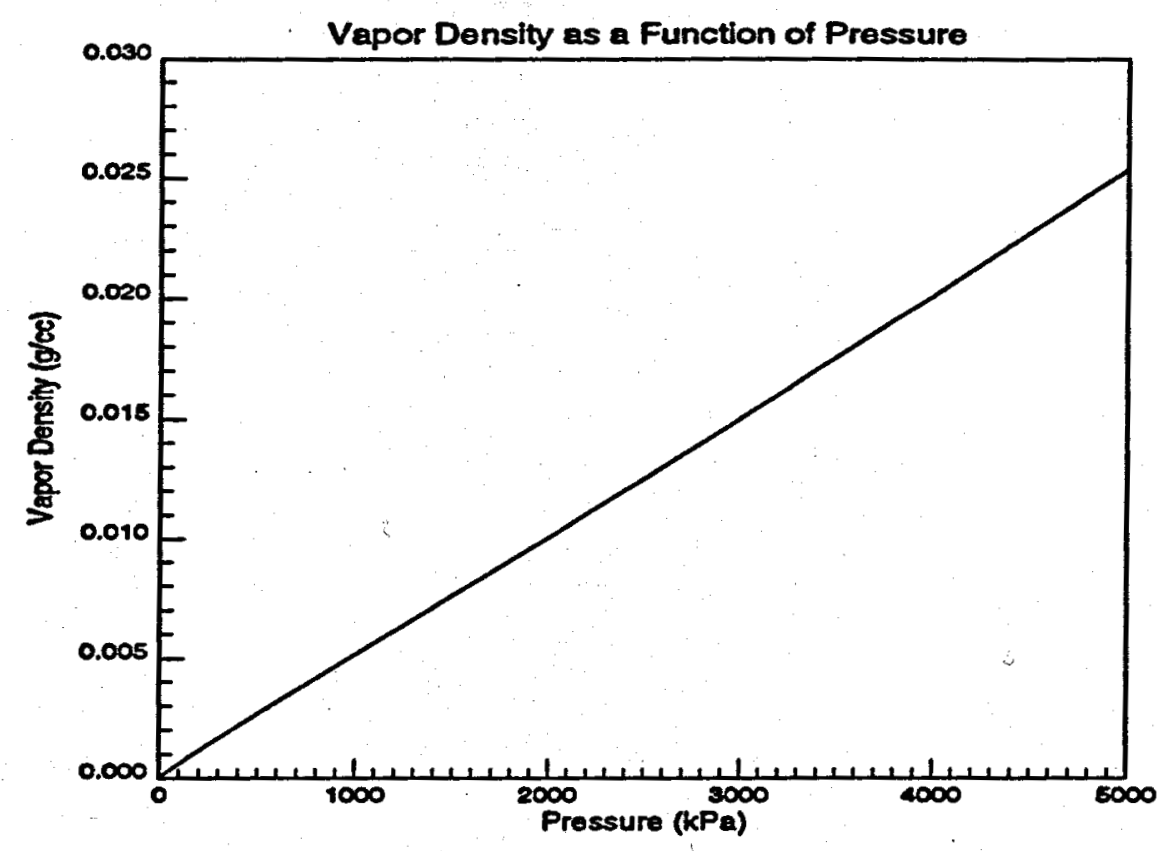

Figure 17: Saturated vapor density

Vapor viscosity over a range of pressures was determined in order to solve the differential equation for fluid flow over a range of pressures. Vapor viscosity is presented in Figure 20.

\subsection{Modelling of the Heat Transfer Mechanism}

The equation for heat transport is given by:

$$
\frac{\partial}{\partial z}\left(K \frac{\partial T}{\partial z}\right)-c_{1} v \frac{\partial T}{\partial z}-L_{v} q_{v}+L_{a} q_{a}+Q=\left[c_{1}+c_{2}+c_{3}\right] \frac{\partial T}{\partial t}-\phi\left(1-S_{w}\right) T \beta \frac{D P}{D t}
$$

The terms in this equation are described as follows:

The rate of change of thermal energy by Fourier conduction:

$$
\frac{\partial}{\partial z} K \frac{\partial T}{\partial z}
$$

The rate of change of thermal energy by vapor flow:

$$
c_{1} v \frac{\partial T}{\partial z}
$$




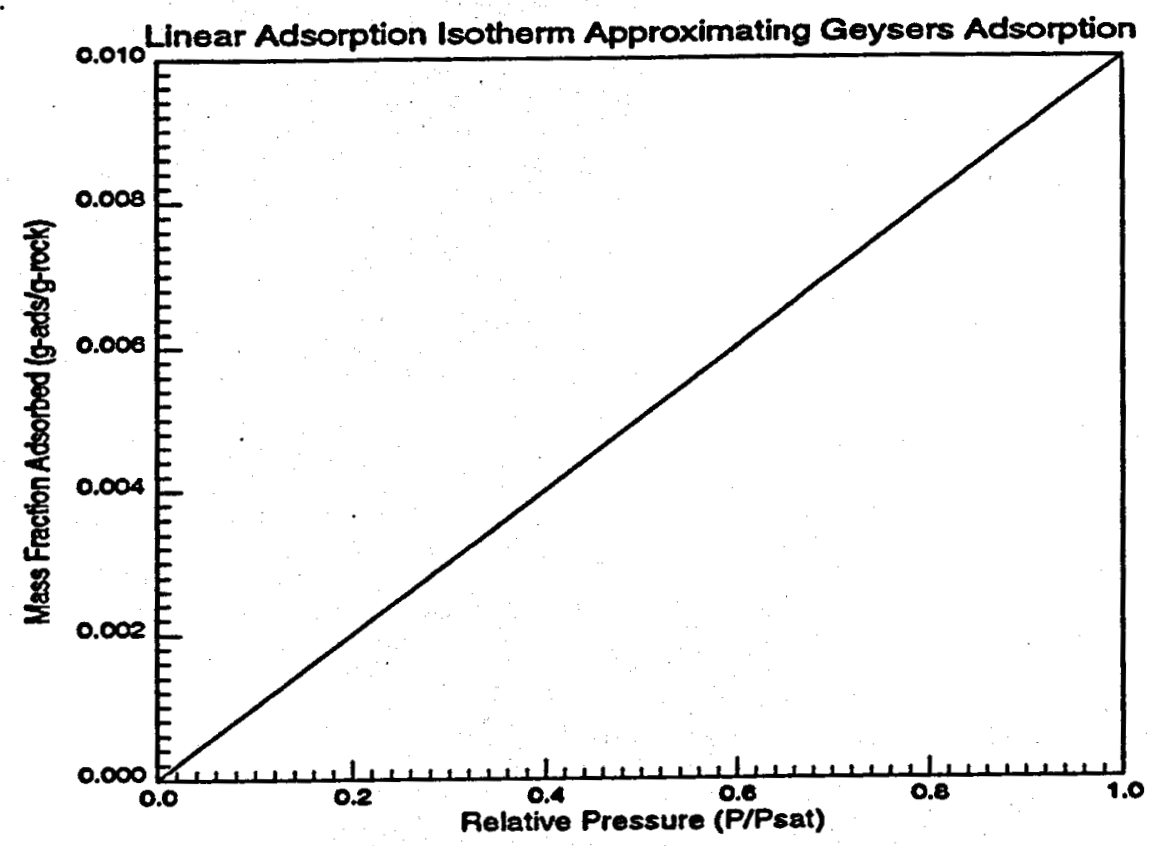

Figure 18: Linear adsorption isotherm

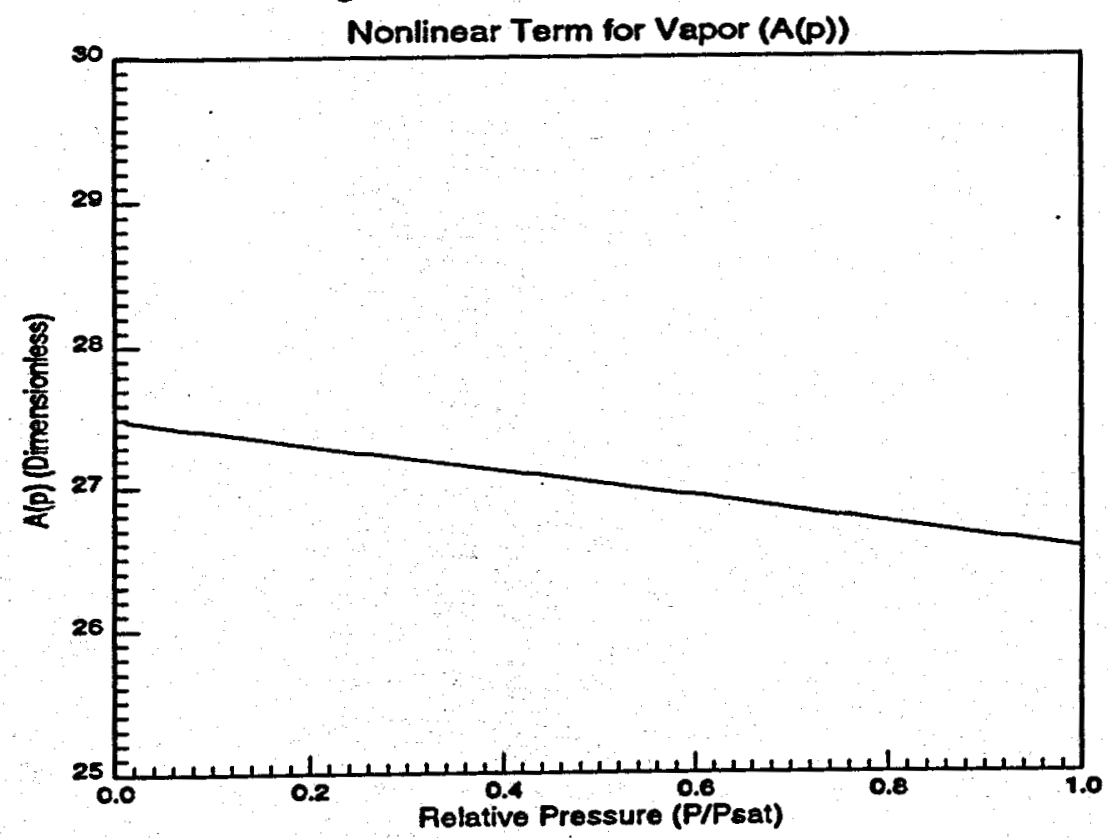

Figure 19: Non-linear term $(A(p))$ for vapor 


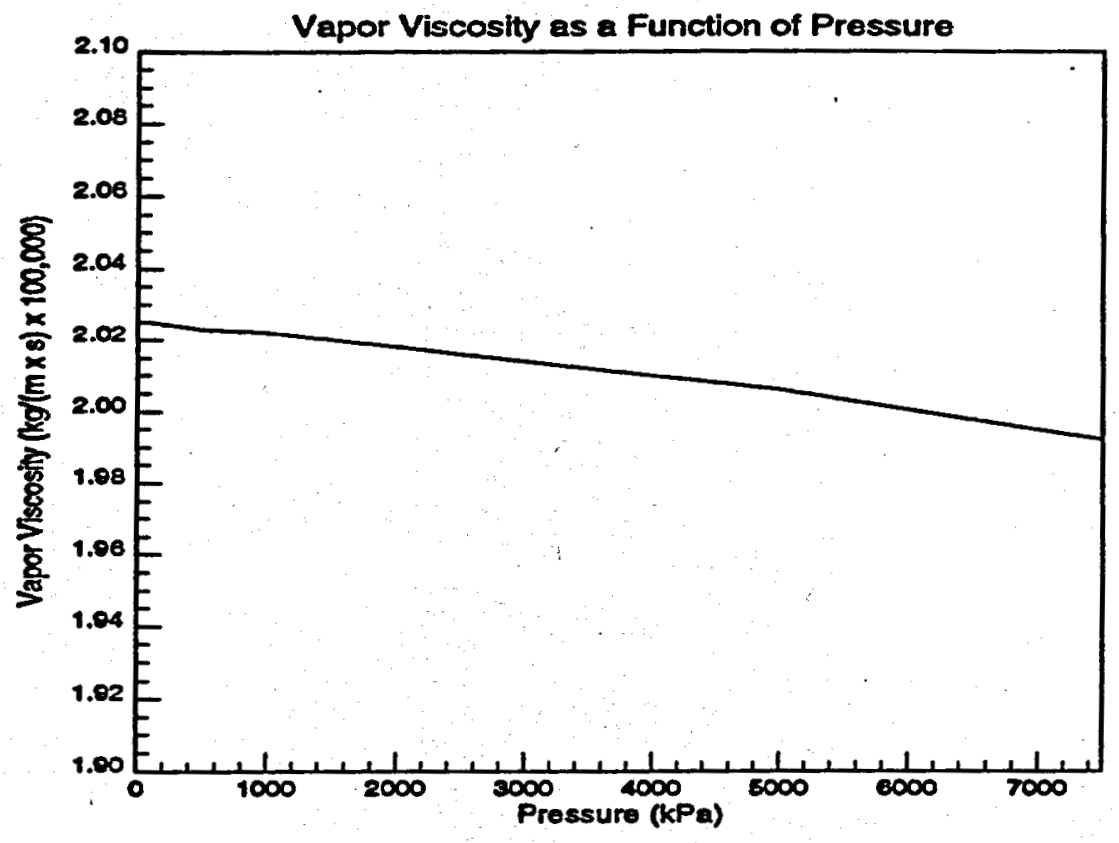

Figure 20: Vapor viscosity for a range of pressures at $300 \mathrm{C}$

The source or sink of thermal energy due to condensation or vaporization:

$$
L_{v} q_{v}
$$

The source or sink of thermal energy due to adsorption or desorption:

$$
L_{a} q_{a}
$$

The source or sink of thermal energy due to fluid withdrawal or loss through boundaries:

\section{$Q$}

The rate of change of thermal energy stored in the vapor, liquid, and solid components:

$$
\left[c_{1}+c_{2}+c_{3}\right] \frac{\partial T}{\partial t}
$$

The rate of change of thermal energy due to compressible work:

$$
\phi(1-S) T \beta \frac{D T}{D t}
$$


where:

$$
\frac{D T}{D t}=\frac{\partial T}{\partial t}+v \frac{\partial T}{\partial x}
$$

The heat equation may be linked to the fluid flow equation by an expression that relates pressure and temperature. Much of the work carried out in the past has assumed flat surface thermodynamics at the vapor/liquid interface and has ignored the vapor-pressure lowering effects of adsorption or capillary retention. In porous media, the vapor pressure is a function, not only of the temperature of the system, but also of the adsorbed or capillary retained liquid. A general expression for the vapor pressure is the following:

$$
p_{v}=p_{0}(T) f\left(S_{a}\right)
$$

where, $\mathrm{f}\left(S_{a}\right)$ is some function of the adsorbate saturation. Eqn. (4) tells us that adsorbate saturation $\left(S_{c}\right)$ is a function of porosity, rock density, adsorbate density, and the mass adsorbed as prescribed by an adsorption isotherm. In Eqn. (4), all terms are constant except the adsorption isotherm $(\mathrm{X}(\mathrm{p}))$ so Eqn. (23) may be rewritten:

$$
p_{v}=p_{0}(T) \text { Const. } f(X(p))
$$

The proper way to deal with the last term, $f(X(p))$ has not yet been determined, but work is continuing in this direction.

\subsection{Investigation of Relative Rates of Fluid and Heat Trans- port}

Work in this section is modeled after the work carried out by Woods and Fitzgerald (1992). Similarity solutions with adsorption effects included are used to study the basic flow characteristics in geothermal systems.

Eqn. (9) may be written as follows in the liquid water saturated region:

$$
\phi \frac{\partial \rho_{w}}{\partial t}+\frac{1}{A(p)} \nabla \cdot\left(u_{w} \rho_{w}\right)=0
$$

If the assumption is made that porosity and permeability are low and the rate of advection of water is, therefore, small, it may be assumed that the rock and water are in thermodynamic equilibrium. The energy balance may then be expressed as a change in enthalpy due to the net advection and diffusion of heat through the surfaces of the control volume: 


$$
\frac{\partial \overline{\rho C_{p}} T}{\partial t}+\nabla \cdot\left(u_{w} \rho_{w} C_{p w} T\right)=\nabla \cdot(\bar{K} \nabla T)
$$

where $C_{p w}$ and $C_{p r}$ are the specific heats of water and rock, respectively,

$$
\overline{\rho C_{p}}=\phi \rho_{w} C_{p w}+(1-\phi) \rho_{r} C_{p r}
$$

$K_{w}$ and $K_{r}$ are the thermal conductivities of the water and rock, respectively, and:

$$
\bar{K}=\phi K_{w}+(1-\phi) K_{r}
$$

Eqn. (28) is an approximation for the mean thermal conductivity as used by Batchelor (1974) and Dullien (1992). Eqn. (26) neglects the heat source or sink due to liquid adsorption or desorption, respectively. An additional term must be included to account for this. Eqn. (26) may be rewritten as:

$$
\frac{\partial \overline{\rho C_{p}} T}{\partial t}+\nabla \cdot\left(u_{w} \rho_{w} C_{p w} T\right)+L_{a} \rho_{a} \frac{d X}{d t}=\nabla \cdot(\bar{K} \nabla T)
$$

By using the chain rule for differentiation, Eqn. (29) may be rewritten:

$$
\frac{\partial \overline{\rho C_{p}} T}{\partial t}+\nabla \cdot\left(u_{w} \rho_{w} C_{p w} T\right)+L_{a} \rho_{a} \frac{d X}{d p} \frac{d p}{d t}=\nabla \cdot(K \nabla T)
$$

\subsection{Investigation of the Influence of Fractures on Fluid Flow}

Work has not yet progressed to the point that the effects of porosity may be evaluated. However, results from these investigations are expected to be of significance to this study.

\subsection{Perturbation Expansion}

As described above, the equation describing flow in porous media is:

$$
\frac{\partial p}{\partial t}=\frac{k}{\phi A(p) \mu_{l}} \nabla \cdot(p \nabla p)
$$

This equation may be simplified by grouping all constants and variables associated with the diffusion coefficient:

$$
\frac{\partial p}{\partial t}=A^{\prime}(p) \nabla \cdot(p \nabla p)
$$


Assuming one-dimensional flow:

$$
\frac{\partial p}{\partial t}=\frac{A^{\prime}(p)}{c_{t}} \frac{\partial^{2} p}{\partial x^{2}}
$$

Where total system compressibility $\left(c_{t}\right)$ is assumed constant and may be absorbed into the nonlinear term. Boundary and initial conditions are:

1. $p(0, t)=p_{0}$

2. $p(L, t)=p_{\infty}$

3. $\mathrm{p}(\mathrm{x}, 0)=p_{\infty}$

The linear diffusion term may be expressed as:

$$
A=A_{0}\left[1+\beta\left(p-p_{0}\right)\right]
$$

where, $A_{0}=\mathrm{A}(\mathrm{p})$ at $\mathrm{p}=p_{0}$. Dimensionless quantities may be defined as follows:

$$
\begin{aligned}
p_{d} & =\frac{p-p_{0}}{p_{\infty}-p_{0}} \\
x_{d} & =x / L \\
t_{d} & =\frac{A_{0} t}{L^{2}} \\
\varepsilon=\beta\left(p_{\infty}-p_{0}\right) & =\frac{A_{\infty}-A_{0}}{A_{0}} \ll 1.0
\end{aligned}
$$

After inserting dimensionless quantities, Eqn. (33) becomes:

$$
\frac{\partial p_{d}}{\partial t_{d}}=\left(1+\epsilon p_{d}\right) \frac{\partial^{2} p_{d}}{\partial x_{d}^{2}}
$$

With boundary and initial conditions:
1. $\mathrm{p}\left(0, t_{d}\right)=0$
2. $\mathrm{p}\left(1, t_{d}\right)=1$
3. $\mathrm{p}\left(x_{d}, 0\right)=1$ 
Now, Eqn. (39) may be expanded in a perturbation series of the form:

$$
p(x, t)=p_{0}(x, t)+\varepsilon p_{1}(x, t)+\varepsilon^{2} p_{2}(x, t)+\ldots
$$

The first term in the expansion is obtained by setting $\varepsilon$ to 0 , thus linearizing Eqn. (39).

$$
\frac{\partial^{2} p_{d 0}}{\partial x_{d}^{2}}-\frac{\partial p_{d 0}}{\partial t_{d}}=0
$$

This equation may be solved by Fourier Sine Transform:

$$
\begin{gathered}
-\alpha^{2} \hat{p}_{d 0}+\alpha p_{d}(x=0)-\frac{d \hat{p}_{d 0}}{d t_{d}}=0 \\
\frac{d \hat{p}_{d 0}}{d t}+\alpha^{2} \hat{p}_{d 0}=0 \\
\hat{p}_{d 0}(t)=e^{-\left(\alpha^{2} t\right)} \\
p_{d 0}(x, t)=\frac{2}{\pi} \int_{0}^{\infty} e^{-\left(\alpha^{2} t\right)} \sin \alpha x d \alpha
\end{gathered}
$$

Evaluation of this integral yields:

$$
p_{d 0}(x, t)=\frac{ \pm x e r f i\left[\frac{|x|}{2 \sqrt{t}}\right]}{\sqrt{\pi t} e^{x^{2} / 4 t}}
$$

The second term in the perturbation expansion is obtained by including $\varepsilon$ and, thus, including nonlinear terms. The equation to be solved for the second term is:

$$
\frac{\partial p_{d 1}}{\partial t_{d}}-\frac{\partial^{2} p_{d 1}}{\partial x_{d}^{2}}=p_{d 0} \frac{\partial^{2} p_{d 0}}{\partial x_{d}^{2}}
$$

With boundary conditions:

1. $p_{1}\left(0, t_{d}\right)=0$

2. $p_{1}\left(1, t_{d}\right)=0$

3. $p_{1}\left(x_{d}, 0\right)=0$

The equation for the second perturbation series term has not yet been solved. Work is continuing in this area at the present time. 


\subsection{Nomenclature}

\begin{tabular}{|c|c|c|}
\hline A & Nonlinear term & dimensionless \\
\hline c & Compressibility & $1 / \mathrm{kPa}$ \\
\hline $\mathbf{C}$ & Heat capacity & $\mathbf{k J} / \mathbf{k g} \cdot \operatorname{deg} \mathrm{C}$ \\
\hline $\mathbf{h}$ & Enthalpy & $\mathrm{kJ} / \mathrm{kg}$ \\
\hline $\mathbf{k}$ & Permeability & md \\
\hline $\mathbf{K}$ & Thermal conductivity & $\mathbf{k J} / \mathbf{s} \cdot \mathbf{m} \cdot \operatorname{deg} C$ \\
\hline $\mathbf{L}$ & Characteristic length & $\mathbf{m}$ \\
\hline$L_{p}$ & Latent heat of phase, $\mathrm{p}$ & $\mathrm{kJ} / \mathrm{kg}$ \\
\hline n & Number of dimensions & dimensionless \\
\hline $\mathbf{p}$ & Pressure & bar \\
\hline $\mathbf{q}$ & Flow rate & $\mathrm{kg} / \mathrm{s}$ or $\mathrm{m}^{3} / \mathrm{s}$ \\
\hline $\mathbf{Q}$ & Flow rate & $\mathrm{kg} / \mathrm{s}$ or $\mathrm{m}^{3} / \mathrm{s}$ \\
\hline $\mathbf{R}$ & Universal gas constant & $\mathrm{kJ} / \mathrm{kmol} \cdot \mathbf{K}$ \\
\hline $\mathbf{S}$ & Stefan Number & dimensionless \\
\hline$B$ & Flow constant & dimensionless \\
\hline $\mathbf{T}$ & Temperature & $\operatorname{deg} \mathrm{C}$ \\
\hline $\mathbf{t}$ & Time & $\mathbf{s}$ \\
\hline $\mathbf{u}$ & Velocity & $\mathbf{m} / \mathbf{s}$ \\
\hline $\mathbf{X}$ & Adsorbed mass & $g_{a} / g_{r}$ \\
\hline $\mathbf{x}$ & Distance & \\
\hline 2 & Real gas compressibility factor & dimensionless \\
\hline$\alpha$ & Fourier variable & dimensionless \\
\hline $\boldsymbol{\beta}$ & Slope of adsorption isotherm & dimensionless \\
\hline$\lambda$ & Ratio of isotherm rate to fluid velocity & dimensionless \\
\hline$\mu$ & Viscosity & \\
\hline$\phi$ & Porosity & dimensionless \\
\hline $\boldsymbol{\rho}$ & Density & g/cc \\
\hline & Reference time & \\
\hline
\end{tabular}




\section{Subscript Meaning}

$\begin{array}{ll}\text { a } & \text { Adsorbate } \\ \text { d } & \text { Dimensionless } \\ \text { g } & \text { Gas } \\ \text { i } & \text { Initial } \\ \text { l } & \text { Liquid } \\ \text { n } & \text { Number of dimensions } \\ \text { o } & \text { Initial or base value } \\ \text { p } & \text { Pressure or Constant pressure } \\ \mathbf{r} & \text { Rock } \\ \text { sat } & \text { Saturated conditions } \\ \mathbf{t} & \text { Total } \\ \text { v } & \text { Vapor } \\ \text { w } & \text { Water } \\ \infty & \text { Infinity }\end{array}$

\section{EARTHTIDE EFFECTS ON DOWNHOLE PRESSURES}

This project is being performed by research assistant Edgar Dias and Prof. Henry J. Ramey, Jr. The aim of the project is to develop a method that utilizes phase shifts observed between exciting tidal forces, and the pressure response to these changes measured downhole in geothermal reservoirs.

\subsection{Earlier Work}

Water level fiuctuations were observed in a flooded abandoned coal mine in Czechoslovakia in 1880. The investigators linked the tidal nature of these changes, to the dilation of the porous media due to earth tides.

Earth tides are caused by the changing gravitational forces exerted on the Earth by the Sun and the Moon, as they move with respect to each other.

Ocean tides had been noted much earlier, as far back as Herodotus(450 B.C). The gravitational theory of Newton led to a scientific explanation of these tides and was elaborated in the equilibrium tide theory.

Earth tides are much smaller than ocean tides. The magnitude of the semi-diurnal dilation being approximately 1.5 E-08. However, they caused 
observable changes upto $2 \mathrm{cms}$ in water levels in wells penetrating the watertable aquifers.

Melchior(1966) reviewed much of the early work done on earth tides. He recorded amplitudes of the water level changes due to these tides in several wells. He performed a harmonic analysis on this data, and derived the amplitudes of the major tidal components of the waves. On comparing the ratios of the amplitudes of the major waves, to that of the large semidiurnal wave, with the ratios predicted from the equilibrium tide theory, he found they compared reasonably well. He thus affirmed the contention of Theis(1939) and others, that the cause of the fluctuations in the water levels were due to earth tides.

Melchior(1966) attempted to find a relationship between the exciting force, and the observed water level fluctuations, using the analysis of Blanchard and Byerley. He found amplitudes based on his analysis, differed largely from those observed. He noted phase shifts of up to 25 degrees, between the theoretical dilation and the harmonic components, which could not be explained.

Several seismologists noted fluctuations in water levels induced by earthquakes. Using different aquifer models, hydrologists sought to use this data as information on aquifer properties. They noted that wells in the same aquifer sometime responded differently to the same disturbance.

Cooper et al.(1965), derived an analytical expression for the nonsteady drawdown in the aquifer, due to a harmonic motion of the water level in the well. They used this with an equation of motion of the water column in the well, to relate the amplitude of the pressure-head change, to the amplitude of the water level. They also derived a similar expression for the effect of vertical motion on the well-aquifer system. They found the latter effect negligible, when compared to the pressure-head change caused by dilation. The differential equation of motion of the water in the well, is similar to that of a mechanical system, subjected to forced vibration with viscous damping. The important parameters controlling the response, were transmissivity, storage coefficient, porosity of the aquifer, and dimensions of the well. The type, period and amplitude of the disturbance were also important.

At large transmissivities, the resonant frequency depends entirely on the height of the water column in the well. The response decreases rapidly for frequencies greater than the resonant frequency. Friction losses in the well and the inertia of the water in the aquifer were neglected in the derivation, an assumption that is justified at the frequencies of the earth tides. Bredehoeft 
et al.(1966) confirmed these assumptions, using electrical analog models to simulate the system. They highlighted factors controlling the damping of the response. For a greater mass of fluid in the well, the critical damping occurred at a lower value of transmissivity. At higher transmissivities, the well would oscillate following a sudden disturbance.

Bredehoeft(1967), highlighted that specific storage and porosity of an aquifer determined why some wells had large responses, and others did not. He showed that, for example, with $r_{w}$ (radius of well-bore) $=1 \mathrm{ft}$, $\mathrm{T}$ (transmissivity) would have to be less than $0.001 \mathrm{ft}^{2} / \mathrm{sec}$, in order that the amplification factor for a 12-hour period wave be less than 0.9 . For waves with periods in excess of $1000 \mathrm{sec}$, the height of the fluid column had practically no effect on amplification. So, for wells in confined aquifers with $T>0.001 \mathrm{ft}^{2} / \mathrm{sec}$, the change in pressure head due to earth tides almost equalled the change in water level in the well. Using a model of an unconfined aquifer, he showed that changes in water levels in such aquifers would be insignificant unless the porosity of the aquifer was very small. He asserted that specific storage and porosity of the aquifer, could be determined from an analysis of the response to earth tides, if the Poisson ratio for the aquifer was known with sufficient accuracy. He showed that modelling the aquifer as an infinite porous medium, rather than a finite cavity, allowed inclusion of the porosity. This explained the discrepancy that the model of Melchior had faced earlier.

Bredehoeft(1967) suggested that the use of accurate downhole pressure gauges to record the response to earth tides, would allow higher accuracy and higher sensitivity to smaller dilations of the order of $1.0 \mathrm{E}-10$ to 1.0 E-11.

Bodvarsson(1970) outlined a general theory that derived expressions for strain-induced fluctuations of downhole pressure. Based on a generalized form of Darcy's law, it included an inertial term. He too noted that measuring pressure down-hole with an accuracy of $2 \mathrm{~mm}$ head of water would indicate dilation of the order of 1.E-09.

Robinson and Bell(1971), reviewed tidal fluctuations in six wells. They expressed dilation of the reservoir as a sum of barometric changes, ocean tides and earth tides, allowing for phase differences to exist between the dilation component, and the respective tide generating potential. They assumed earth tide dilation to be in phase with the tide generating potential. They eliminated the effect of ocean tides by assuming the ratio of the principal lunar and semidiurnal constituents to be the same for the ocean tides as for the corresponding aquifer dilation. After filtering out the nontidal and 
barometric effects, the dominant M2 and 02 constituents were computed by a least-8quares harmonic analysis. They listed amplitudes and phase differences, the latter being considered unreliable due to nontidal pressure changes. They calculated porosity of the aquifer and claimed an accuracy of $+1.5 \%$, the main limitation being an accurate input value for the matrix bulk modulus. Ocean tide effects would decrease the claimed accuracy. Marine(1975) highlighted practical difficulties in calculating porosity by the preceding methods, in crystalline metamorphic rocks, and coastal plain sediments. Rhoads and Robinson(1979) developed a similar expression between specific storage and the earth tide generating potential.

With the advent of high sensitivity quartz crystal gauges in interference testing, Strobel et al.(1976) measured earth tide responses during an interference test. Khurana(1976) noted oscillations of 0.1 psi on downhole pressure records, measured during well-test evaluation. He indicated that they affected the accurate interpretation of long duration pressure buildup tests, and pulse tests of small response magnitudes and long time lags. Witherspoon(1978) used a similar pressure gauge, and noted changes of $0.1 \mathrm{psi}$ which were phase shifted form the gravity variations that induced them.

Arditty et al.(1978) described the pressure response to earth tides in a closed well-reservoir system. Using a model of the well as a cavity in a nonporous formation and effective pressures, they determined an expression for a critical frequency, above which the response to earth tides decreased rapidly. The parameters controlling the response were the permeability and porosity of the formation and the rock and the fluid compressibilties.

Hemala and Balnaves(1988) observed ocean tide effects with amplitudes of 1.0 psi during well tests. These were 70 times larger than the barometric and earth tide effects. They derived an expression for the tidal efficiency, in terms of specific storage, and the compressibilities of the fiuid, the rock the pore and the total compressibility. They used a one-dimensional gas-water contact model and changed the effective pore volume by injecting or withdrawing an appropriate amount of fluid from the individual cells to simulate the response to earth tides. They showed that the tidal efficiency would vary across the fluid contact, and also predicted a change in phase of the pressure oscillation across the interface. They noted that detection of such a shift was an indicator of the existence of a similar fluid contact, and that vertical permeability played an important factor in tidal effects. Wanell et al.(1990) derived vertical permeability of a reservoir using the pressure changes due to ocean tides across a gas-liquid interface. The pressure changes were inversely proportional to the compressibility of the fluid in the reservoir pores. 
This caused a pressure change transition zone across the gas-liquid interface. Pressure changes outside the transition zone, were used to measure pore volume compressibility. A simulation of the cyclic changes indicated that the gas-liquid contact would move in response to the tidal effects. The shape of the gas-liquid contact pressure change transition zone could be used to determine vertical permeability.

\subsection{Mathematical Description .}

We attempt to derive an expression, which describes a model of fluid flow in a porous medium that is subject to dilation.

We can start with the equation derived by Biot(1941) which relates pressure to the displacement velocity $v_{A}$ of the solid medium:

$$
\left(\frac{k}{\rho_{B} g}\right) \nabla^{2} p=\operatorname{div} v_{A}+\phi \beta^{\prime}\left(\frac{\partial p}{\partial t}\right)
$$

where

$$
\beta^{\prime}=\beta+\frac{1-S_{r}}{p}
$$

$\left(1-S_{r}\right) \ll 1$ and

$$
v_{A}=\frac{\partial u_{A}}{\partial t}
$$

where $u_{A}$ is the displacement vector of the solid material. this can be rewritten as:

$$
\left(\frac{k}{\rho g}\right) \nabla^{2} p=\frac{\partial e}{\partial t}+\phi \beta^{\prime}\left(\frac{\partial p}{\partial t}\right)
$$

where $e$ is the volume strain $e=\operatorname{div} u_{A}$ There are two variables, volume strain $e$ and fiuid pressure $p$, and one equation. Another equation is sought to allow the derivation:

We attempt to obtain this additional equation from the mechanics of the soil structure and incorporate the effect of dilation due to earth tides in the relationship. Components of total stress $\sigma_{i j}$ indicate the stress component acting in direction $i$ on the element face having inormal to the plane in direction $\mathrm{j}$. Total stress can be related to effective stress as follows: In cylindrical coordinates:

$$
\begin{aligned}
& \sigma_{r r}=\sigma_{r r}^{\prime}-\sigma \\
& \sigma_{\theta \theta}=\sigma_{\theta \theta}^{\prime}-\sigma \\
& \sigma_{z z}=\sigma_{z z}^{\prime}-\sigma
\end{aligned}
$$




$$
\begin{aligned}
& \sigma_{\theta z}=\sigma_{\theta z}^{\prime} \sigma_{z \theta}=\sigma_{z \theta}^{\prime} \\
& \sigma_{z r}=\sigma_{z r}^{\prime} \sigma_{r z}=\sigma_{r z}^{\prime} \\
& \sigma_{r \theta}=\sigma_{r \theta}^{\prime} \sigma_{\theta r}=\sigma_{\theta r}^{\prime}
\end{aligned}
$$

where $\sigma^{\prime}$ denotes effective pressures.

From Hooke's Law,

$$
\begin{aligned}
\sigma_{r r}^{\prime} & =2 \mu \epsilon_{r r}+\lambda \epsilon \\
\sigma_{\theta \theta}^{\prime} & =2 \mu \epsilon_{\theta \theta}+\lambda \epsilon \\
\sigma_{z z}^{\prime} & =2 \mu \epsilon_{z z}+\lambda \epsilon \\
\sigma_{\theta z}^{\prime} & =2 \mu \epsilon_{\theta z} \\
\sigma_{z r}^{\prime} & =2 \mu \epsilon_{z r} \\
\sigma_{r \theta}^{\prime} & =2 \mu \epsilon_{r \theta}
\end{aligned}
$$

in grational forces due to earth Lame coefficient. tides as:

$$
g=g_{0}(1+g \exp i \omega t)
$$

$10^{-7}$ and $\omega$ are different frequency components of the earth tides.

where $g \sim 10^{-7}$ and $\omega$ are diftens of equilibrium as follows in cylindricat coordinates:

$$
\begin{aligned}
\frac{\partial \sigma_{r r}}{\partial r}+\frac{1}{r} \frac{\partial \sigma_{r \theta}}{\partial \theta}+\frac{\partial \sigma_{r z}}{\partial z}+\frac{\sigma_{r r}-\sigma_{\theta \theta}}{r} & =0 \\
\frac{\partial \sigma_{\theta r}}{\partial r}+\frac{1}{r} \frac{\partial \sigma_{\theta \theta}}{\partial \theta}+\frac{\partial \sigma_{\theta z}}{\partial z}+2 \frac{\sigma_{\theta r}}{r} & =0 \\
\frac{\partial \sigma_{z r}}{\partial r}+\frac{1}{r} \frac{\partial \sigma_{z \theta}}{\partial \theta}+\frac{\partial \sigma_{z z}}{\partial z}+\frac{\sigma_{z r}}{r}+P_{z} & =0 \\
\sigma_{\theta z} & =\sigma_{z \theta} \\
\sigma_{z} r & =\sigma_{r z} \\
\sigma_{z \theta} & =\sigma \theta z
\end{aligned}
$$


We have assumed that inertia is negligible at the earth tide frequencies, also the body forces in the $r$ and $\theta$ directions are nonexistent.

Now substituting the effective pressures in these relationships we obtain:

$$
\begin{aligned}
\frac{\partial \sigma_{r r}^{\prime}}{\partial r}+\frac{1}{r} \frac{\partial \sigma_{r \theta}^{\prime}}{\partial \theta}+\frac{\partial \sigma_{r z}^{\prime}}{\partial z}+\frac{\sigma_{r r}^{\prime}-\sigma_{\theta \theta}^{\prime}}{r} & =\frac{\partial \sigma}{\partial r} \\
\frac{\partial \sigma_{\theta r}^{\prime}}{\partial r}+\frac{1}{r} \frac{\partial \sigma_{\theta \theta}^{\prime}}{\partial \theta}+\frac{\partial \sigma_{\theta z}^{\prime}}{\partial z}+2 \frac{\sigma_{\theta r}^{\prime}}{r}= & \frac{1}{r} \frac{\partial \sigma}{\partial \theta} \\
\frac{\partial \sigma_{z r}^{\prime}}{\partial r}+\frac{1}{r} \frac{\partial \sigma_{z \theta}^{\prime}}{\partial \theta}+\frac{\partial \sigma_{x z}^{\prime}}{\partial z}+\frac{\sigma_{z r}^{\prime}}{r}+P_{z} & =\frac{\partial \sigma}{\partial z} \\
\sigma_{\theta z}^{\prime} & =\sigma_{z \theta}^{\prime} \\
\sigma_{z r}^{\prime} & =\sigma_{r z}^{\prime} \\
\sigma_{z \theta}^{\prime} & =\sigma_{\theta z}^{\prime}
\end{aligned}
$$

Now assuming axial geometry and knowing that:

$$
\begin{aligned}
u_{\theta} & =0 \\
\frac{\partial u_{r}}{\partial \theta} & =0 \\
\frac{\partial u_{z}}{\partial \theta} & =0 \\
\frac{\partial \sigma}{\partial \theta} & =0
\end{aligned}
$$

We get simplified expressions for the strain in terms of displacement as:

$$
\begin{array}{r}
\epsilon_{r r}=\frac{\partial u_{r}}{\partial r} \\
\epsilon_{\theta \theta}=\frac{u_{r}}{r} \\
\epsilon_{z z}=\frac{\partial u_{z}}{\partial z} \\
\epsilon_{\theta z}=0 \\
\epsilon_{z r}=\frac{1}{2}\left(\frac{\partial u_{z}}{\partial r}+\frac{\partial u_{r}}{\partial z}\right. \\
\epsilon_{r \theta}=0
\end{array}
$$


and the stresses simplify to:

$$
\begin{array}{r}
\sigma_{r r}^{\prime}=2 \mu\left(\frac{\partial u_{r}}{\partial r}+\lambda \epsilon\right. \\
\sigma_{\theta \theta}^{\prime}=2 \mu\left(\frac{u_{r}}{r}\right)+\lambda \epsilon \\
\sigma_{z z}^{\prime}=2 \mu\left(\frac{\partial u_{z}}{\partial z}\right)+\lambda \epsilon \\
\sigma_{\theta z}^{\prime}=0 \\
\sigma_{z r}^{\prime}=\mu\left(\frac{\partial u_{z}}{\partial r}+\frac{\partial u_{r}}{\partial z}\right) \\
\sigma_{r \theta}^{\prime}=0
\end{array}
$$

and volumetric strain can be expressed as:

$$
\epsilon=\frac{\partial u_{r}}{\partial r}+\frac{u_{r}}{r}+\frac{\partial u_{z}}{\partial z}
$$

The equilibrium equations simplify to the following:

$$
\begin{array}{r}
\frac{\partial \sigma_{r r}^{\prime}}{\partial r}+\frac{1}{r} \partial \sigma_{r z}^{\prime} \partial z+\frac{\sigma_{r r}^{\prime}-\sigma_{\theta \theta}^{\prime}}{r}=\frac{\partial \sigma}{\partial r} \\
\frac{\sigma_{\theta \theta}^{\prime}}{\partial \theta}=0 \\
\frac{\partial \sigma_{z r}^{\prime}}{\partial r}+\frac{\partial \sigma_{z z}^{\prime}}{\partial z}+\frac{\sigma_{z r}^{\prime}}{r}+P_{z}=\frac{\partial \sigma}{\partial z}
\end{array}
$$

Let us denote

$$
\sigma_{z z}=2 C \exp i \omega t
$$

this attempts to qualify the vertical change in stress as a sinusoidal variation with the same frequency as the exciting tidal force. Then,

$$
\begin{aligned}
& \sigma_{z z}^{\prime}=\sigma_{z z}+\sigma \\
= & 2 C \exp i \omega t+\sigma
\end{aligned}
$$

We assume now that

$$
\sigma_{r z}=0
$$

then

$$
\sigma_{r z}^{\prime}=0
$$


that is no slip occurs in the radial direction.

Then,

$$
\frac{\partial \sigma_{r r}^{\prime}}{\partial r}+\frac{\sigma_{r r}^{\prime}-\sigma_{\theta \theta}^{\prime}}{r}=\frac{\partial \sigma}{\partial r}
$$

Substituting displacements and the relationship between stresses and strains in the above equation we obtain:

$$
2 \mu \frac{\partial}{\partial r}\left(\frac{\partial u_{r}}{\partial r}+\frac{u_{r}}{r}\right)+\lambda \frac{\partial \epsilon}{\partial r}-\frac{\partial \sigma}{\partial r}=0
$$

and integrating this equation we obtain:

$$
2 \mu\left(\frac{\partial u_{r}}{\partial r}+\frac{u_{r}}{r}\right)+\lambda \epsilon-\sigma=2 F(t, z)
$$

where $F(t, z)$ is a constant of integration now

$$
2 C \exp i \omega t+2 \mu\left(\frac{\partial u_{r}}{\partial r}+\frac{u_{r}}{r}=(\lambda+2 \mu) \epsilon-\sigma\right.
$$

and

$$
C \exp i \omega t+F(t, z)=(\lambda+\mu) \epsilon-\sigma
$$

or,

$$
\epsilon=\frac{\sigma}{\lambda+\mu}+\frac{F(t, z)+C \exp i \omega t}{\lambda+\mu}
$$

This is the relation we were looking to add to the Biot equation we started with. Then,

$$
\frac{k}{\rho g} \nabla^{2} \sigma=\left(\alpha+\phi \beta^{\prime}\right) \frac{\partial \sigma}{\partial t}+\alpha F(t, z)+\alpha C \exp i \omega t
$$

where:

$$
\alpha=\frac{1}{\lambda+\mu}
$$

We will attempt to utilize this form of the equation in further derivation using earth tides. 


\subsection{Nomenclature}

$T_{w}=$ Radius of well bore

$T=$ Transmissivity of the reservoir

$e=$ Volume strain

$S_{r}=$ Fluid Saturation

$\rho_{b}=$ Bulk density

$k=$ Permeability coefficient

$v_{A}=$ Displacement velocity of the solid medium

$u_{A}=$ Displacement vector of the solid material

$\phi=$ Porosity

\section{PRESSURE TRANSIENT AND TRACER TEST ANALYIS IN HETEROGENOUS RESERVOIRS}

This investigation is performed by research assistant, Xianfa Deng, and Prof. Roland N. Horne. The objective of the project is to investigate the simultaneous interpretation of both pressure transient and tracer test data to obtain more information about a geothermal reservoir. At the present stage, the focus is on the use of the Green's function method in heterogeneous reservoirs and the determination of the conditions under which the reciprocity property holds in this case.

\subsection{Introduction}

Using the Green's function method to solve linear ordinary and partial differential equations is not a new idea. Starkgold (1979) and Roach (1982) showed some examples using this method for equations of parabolic and hyperbolic equations with constant coefficients. De Wiest (1969) used this method in a problem of water flowing through porous media. Gringarten and Ramey (1973) made this approach practically usable in petroleum engineering by giving tables of Green's functions for pressure diffusion in homogeneous or anisotropic reservoirs. Carslaw and Jaeger (1959) discussed the Green's function approach for problems of heat conduction, however their definition of the Green's function may not be consistent if used for composite or heterogeneous region.

The Green's function or fundamental function represents the infiuence or response of a system to a unit load or source. The total response is the linear superposition through integration of the responses throughout the system, 
thus the method is restricted to linear systems.

The principle of reciprocity is frequently useful in understanding reservoir physics. McKinley and Vela (1968) investigated the effect of this property in the analysis of interference well testing. Ogbe (1984) studied this principle in the presence of wellbore storage and skin effect for an infinite reservoir. McKinley and Vela (1968) proved that this principle is held if the mobility and storativity are continuously distributed. We show that the principle can also be extended to discontinuous distributions of reservoir properties.

\subsection{Green's Functions for Heterogenous Reservoirs}

The Green's function is defined as a function $G\left(x, y, z, x^{\prime}, y^{\prime}, z^{\prime}, t-\tau\right)$ satisfying the following equation,

$$
\begin{gathered}
\frac{\partial}{\partial x} \frac{k(x, y, z)}{\mu(x, y, z)} \frac{\partial G}{\partial x}+\frac{\partial}{\partial y} \frac{k(x, y, z)}{\mu(x, y, z)} \frac{\partial G}{\partial y}+\frac{\partial}{\partial z} \frac{k(x, y, z)}{\mu(x, y, z)} \frac{\partial G}{\partial z}=\phi(x, y, z) c_{t}(x, y, z) \frac{\partial G}{\partial t} \\
G\left(x, y, z, x^{\prime}, y^{\prime}, z^{\prime}, 0\right)=\frac{\delta\left(x-x^{\prime}\right) \delta\left(y-y^{\prime}\right) \delta\left(z-z^{\prime}\right)}{\phi\left(x^{\prime}, y^{\prime}, z^{\prime}\right) c_{t}\left(x^{\prime}, y^{\prime}, z^{\prime}\right)}
\end{gathered}
$$

The Newman's product theorem (1936) does not hold in heterogeneous reservoirs. So, there is a major restriction to the use of Green's functions for heterogeneous reservoirs. The Green's functions have to be found individually, instead of being constructed from existing easier solutions. This restriction comes from the fact that the domain cannot be decomposed as in the homogeneous case, for instance, a cubic region(three-dimensional) is no longer the product of three intervals which are one-dimensional.

On the other hand, once the Green's function is worked out, the solution to the equivalent nonhomogeneous equation with nonhomogeneous initial condition and nonhomogeneous boundary conditions can be represented by the Green's function,

$p(x, y, z, t)=\int_{0}^{t} \int_{\Omega} G \cdot f d x^{\prime} d y^{\prime} d z^{\prime} d \tau-\int_{0}^{t} \int_{S e} \frac{k}{\mu}\left(G \frac{\partial p}{\partial n}+p \frac{\partial G}{\partial n}\right) d S e d \tau+\int_{\Omega} \phi c_{t} G(t) \cdot g d x^{\prime} d y^{\prime} d z^{\prime}$

If the domain is infinite and has no boundary, then the second term in the right hand side will disappear.

We can easily apply this equation to the production of a well at a flow rate q. Remember in the material balance equation, the source term $f(x, y, z, t)$ 
has the unit volume rate of injection per unit volume of reservoir, so

$$
f(x, y, z, t)= \begin{cases}\frac{g}{V_{w}} & \text { in the well } \\ 0 & \text { out of well }\end{cases}
$$

if the source is uniform over the well volume. Assuming the boundary is no-flow, then

$p(x, y, z, t)=\int_{0}^{t} \int_{W} \frac{q(\tau)}{\pi r_{w}^{2} h} G\left(x, y, z, x^{\prime}, y^{\prime}, z^{\prime}, t-\tau\right) d x^{\prime} d y^{\prime} d z^{\prime} d \tau+\int_{\Omega} \phi c_{t} G(t) \cdot g d x^{\prime} d y^{\prime} d z^{\prime}$,

where $W$ is the region in the well, and $\Omega$ is the domain of reservoir. Now if the initial pressure is constant $p_{i}$ everywhere, we have

$$
p_{i}-p(x, y, z, t)=\int_{0}^{t} \int_{W} \frac{q(\tau)}{\pi r_{w}^{2} h} G\left(x, y, z, x^{\prime}, y^{\prime}, z^{\prime}, t-\tau\right) d x^{\prime} d y^{\prime} d z^{\prime} d \tau
$$

For three dimensions, if the.well is approximated by a point source at position $x^{\prime}, y^{\prime}, z^{\prime}$, the solution becomes

$$
p_{i}-p(x, y, z, t)=\int_{0}^{t} \frac{q(\tau)}{\pi r_{w}^{2} h} G\left(x, y, z, x^{\prime}, y^{\prime}, z^{\prime}, t-\tau\right) d \tau
$$

For two dimensions, if the well is approximated by a line source at $x^{\prime}, y^{\prime}$, the solution is

$$
p_{i}-p(x, y, t)=\int_{0}^{t} \frac{q(\tau)}{\pi r_{w}^{2} h} G\left(x, y, x^{\prime}, y^{\prime}, t-\tau\right) d \tau
$$

For one dimension, if the well is approximated by a plane source at $x^{\prime}$, the solution is then

$$
p_{i}-p(x, y, z, t)=\int_{0}^{t} \frac{q(\tau)}{\pi r_{w}^{2} h} G\left(x, x^{\prime}, t-\tau\right) d \tau
$$

\subsection{Principle of Reciprocity}

The reciprocity for Green's function is proved first by calculus of variations. Once reciprocity holds for the Green's function, we can start to investigate under which conditions the pressure response is reciprocal. Suppose there are two wells, well $A$ produces at some rate, which causes a pressure response at well $B$. Under which conditions, will the pressure response at well A be 
the same if well B is produced at that rate? The pressure can be represented by the Green's function as:

$$
p(x, y, z, t)=\int_{0}^{t} \int_{\Omega} G \cdot f d x^{\prime} d y^{\prime} d z^{\prime} d \tau-\int_{0}^{t} \int_{S e} \frac{k}{\mu}\left(G \frac{\partial p}{\partial n}+p \frac{\partial G}{\partial n}\right) d S e d \tau+\int_{\Omega} \phi c_{t} G(t) \cdot g d x^{\prime} d y^{\prime} d z^{\prime}
$$

In order to satisfy reciprocity, the last two terms on the right hand side have to be zero, i.e. the initial pressure is zero everywhere and boundary is no-flow or kept at constant zero pressure. From this, considering the pressure drop instead of the pressure response itself, we see that reciprocity also holds for the pressure response if the initial pressure is uniform and the boundary is kept at the initial pressure or the boundary is no-flow. For infinite reservoirs, the boundary terms disappears, and only uniform initial pressure condition is required. Notice that these conditions are also necessary conditions. So if the initial pressure distribution is not uniform, or when there is a boundary, at which the pressure is not kept at initial pressure then we do not have reciprocal pressure responses.

Skin factor does not change reciprocity, since the reservoir is treated as a composite reservoir when skin is present. However, from the discussion above, we know that reciprocity holds for the composite reservoir which is a special case of heterogeneity.

When wellbore storage effect is considered, the condition for reciprocity to hold is:

$$
\overline{G_{1}}\left(x_{1\ulcorner D}, y_{1 r D}, x_{1 D}, y_{1 D}, s\right)=\overline{G_{2}}\left(x_{2 r D}, y_{2 r D}, x_{2 D}, y_{2 D}, s\right) \text {. }
$$

In infinite homogeneous reservoir, this can always be satisfied since

$$
\bar{G}\left(x_{D}, y_{D}, x_{1 D}, y_{1 D}, s\right)=\bar{G}\left(x_{D}-x_{1 D}, y_{D}-y_{2 D}, s\right) \text {. }
$$

For other cases, even in homogeneous reservoirs, the wellbore storage may invalidate the reciprocity as shown by the following example.

In a one-dimensional homogeneous reservoir, with a no-flow boundary at $x=0$ and $x=x_{e}$, The Green's function is like

$$
G\left(x, x^{\prime}, t-\tau\right)=\frac{1}{x_{e}}\left[1+2 \sum_{n=1}^{\infty} e^{-\frac{x^{2} x^{2} n t}{x_{e}^{2}}} \cos \frac{n \pi x^{\prime}}{x_{e}} \cos \frac{n \pi x}{x_{e}}\right]
$$

For reciprocity to hold we would need

$$
G\left(x_{1 w}, x_{1}, t\right)=G\left(x_{2 w}, x_{2}, t\right)
$$


or

$$
\cos \frac{n \pi x_{1 w}}{x_{e}} \cos \frac{n \pi x_{1}}{x_{e}}=\cos \frac{n \pi x_{2 w}}{x_{e}} \cos \frac{n \pi x_{2}}{x_{e}}
$$

Assuming $x_{1 w}=x_{1}+x_{w}$ and $x_{2 w}=x_{2}+x_{w}$, then we would need:

$$
\cos \frac{n \pi\left(x_{1}+x_{w}\right)}{x_{e}} \cos \frac{n \pi x_{1}}{x_{e}}=\cos \frac{n \pi\left(x_{2}+x_{w}\right)}{x_{e}} \cos \frac{n \pi x_{2}}{x_{e}}
$$

which is not true, hence reciprocity does not hold.

The next stage of the work will be turning these theoretical results into application, such as to interpret multiple-well interference testing in the Ohaaki geothermal field.

\subsection{Nomenclature}

$$
\begin{aligned}
c_{t} & =\text { compressibility } \\
C & =\text { wellbore storage coefficient } \\
f & =\text { general function } \\
g & =\text { general function } \\
G & =\text { Green's function } \\
h & =\text { thickness } \\
I, K & =\text { modified Bessel functions } \\
k & =\text { permeability } \\
n & =\text { outward normal direction } \\
p & =\text { pressure } \\
q & =\text { flow rate } \\
r_{w} & =\text { wellbore radius of active well } \\
s & =\text { Laplace variable } \\
S & =\text { skin factor } \\
S_{e} & =\text { boundary, integral variable on boundary } \\
t & =\text { time } \\
u & =\text { general function } \\
v & =\text { general function } \\
W & =\text { region in the well } \\
x, y & =\text { coordinates in Cartesian system } \\
\boldsymbol{\mu} & =\text { viscosity } \\
\tau & =\text { time integral variable } \\
\Omega & =\text { reservoir domain, integral variable } \\
\phi & =\text { porosity }
\end{aligned}
$$




\section{References}

- Adamson, A. W.: Physical Chemistry of Surfaces, John Wiley and Sons; Inc., 5th ed., 1990.

- Arditty, P.C., Ramey, H.Jr., and Nur, A.M.: Response of a Closed Well- Reservoir System to Stress Induced by Earth Tides, SPE 7484, 53rd Annual Technical Conference, Houston,(1-3 Oct 1978)

- Batchelor, G. K.: Transport Properties of Two-Phase Materials with Random Structure, Annual Review of Fluid Mechanics, vol. 6, pp. 227-255, 1974.

- Biot, A.M.: General Theory Of Consolidation, Journal Of Applied Physics, Vol 12, Feb 1941.

- Bodvarsson, G.: Confined Fluids As Strain Parameters, J. Geoph Res, Vol 75(14), 1970, 2711-2718.

- Bredehoeft, J.D., Cooper, H.H., and Papadopulos, I.S.: Inertial and Storage Effects in Well-Aquifer Systems and Analog Investigations, Water Resources Research, Vol 2(4),1966,697-707

- Bredehoeft, J.D.: Response of Well-Aquifer Systems to Earth Tides, J. Geoph Res, Vol 72(12) (June 1967), 3075-3087.

- Calhoun, J. C. and Lewis, M. Jr.: Experiments on the Capillary Properties of Porous Solids, Trans. AIME, 1949.

- Carslaw, H. S. and Jaeger, J. C.: Conduction of Heat in Solids, 2nd edition, Oxford University Press (1959).

- Cooper, H.H.Jr., Bredehoeft, J.D., Papadopulos, I.S, and Bennett, R.R.: The Response of the Well-Aquifer Systems to Seismic Waves, J. Geoph Res, Vol 70(16),1965,3915-3926.

- Courant, C. and Hilbert, D.: Methods of Mathematical Physics Volume I, Interscience Publishers, Inc. (1953).

- Crank, J.: The Mathematics of Diffusion, Oxford, Clarendon Press, 1964

- De Wiest, R.J.M.: On the Storage Coefficient and the Equations Of Groundwater Flow, J Geophy Res, Vol 71, No 4, Feb 1966. 
- De Wiest, R.J.M.: Flow Through Porous Media, Academic Press (1969).

- Doughty, C. and Pruess, K.: A Similarity Solution for Two-Phase Water, Air, and Heat Flow near a Linear Heat Source in a Porous Media, Journal of Geophysical Research, vol. 97, no. B2, pp. 18211838, Feb. 10, 1992.

- Dullien, F. A. L.: Porous media - fluid transport and pore structure, Academic Press, pp. 1-574, 1992.

- Ejiogu, G.C. and Fiori, M.: High-Pressure Saturated Steam Correlations, Journal of Petroleum Technology, December (1987).

- Fitzgerald, S. D. and Woods, A. W.: The injection of water into and extraction of vapour from a geothermal reservoir, Cambridge University, England, Unpublished report, July, 1992.

- Fitzgerald, S. D. and Woods, A. W.: Vapour generation in hot permeable rock through injection of water, Proceedings: Seventeenth Workshop on Geothermal Reservoir Engineering, Stanford University, Jan., 1992.

- Fung, Y.C:Foundations Of Solid Mechanics, Prentice-Hall Inc, June 1965.

- Harr, M. S.: Laboratory Measurement of Sorption in Porous Media, Master's Report, Stanford University, August, (1991).

- Hemala, M.L., and Balnaves, C.: Tidal Effects in Petroleum Well Testing, SPE 14607, presented at SEAC, Singapore, (28-31 Jan 1986).

- Herkelrath, W. N., Moench, A. N., and C. F. O'Neal II: Laboratory Investigations of Steam Flow in a Porous Medium, Water Resources Research, vol. 19, no. 4, pp. 931-937, 1983.

- Hsieh, C. H. and Ramey, H. J.Jr.: Vapor-Pressure Lowering in Geothermal Systems, no. 9926, SPE Annual Technical Conference, Bakersfield, CA, Nov. 15, 1981.

- Gringarten, A. and Ramey, H.: The Use of Source and Green's Functions in Solving Unsteady-Flow Problems in Reservoirs, Soc. of Petroleum Engineering Journal (October 1973) 285-296. 
- Khurana, A.K.: Influence of Tidal Phenomena on the Interpretation of Pressure Build-Up and Pulse tests, APEA Journal, 16/1(1976) 99-105.

- Lai, M.W., Rubin, D., and Krempl, E.:Continuum Mechanics, Pergamon Press, Vol 17.

- Marine, I.W.: Water Level Fluctuations due to Earth Tides in a Well Pumping From Slightly Fractured Crystalline Rock, Water Resources Research,(Feb 1975), 165-173.

- Mckinley, R. M., Vela, S. and Carlton, L. A.: A Field Application of Pulse-Testing for Detailed Reservoir Description, J. Pet. Tech. (March 1968) 313-321.

- Melchior, P.:The Earth Tides, 458 pp., Pergamon, New York,1966.

- Moench, A. F.: Simulation of steam transport in vapor-dominated geothermal reservoirs, USGS, no. 76-607, Menlo Park, CA, 1976.

- Moench, A. F. and Atkinson, P. F.: Transient-Pressure Analysis in Geothermal Steam Reservoirs with an Immobile Vaporizing Liquid Phase, Geothermics, vol. 00, no. 7, pp. 253-264, 1978.

- Nghiem, C.P. and Ramey, H.J.Jr.: One-Dimensional Steam Flow in Porous Media, SGP No. TR-132, Stanford Geothermal Program, Stanford University, (1991).

- Newman, A. B.: Heating and Cooling Rectangular and Cylindrical Solids, Ind. and. Eng. Chem. (1936) 28, 545.

- Ogbe, D. O.: Pulse Testing in the Presence of Wellbore Storage and Skin Effects, PhD dissertation, Stanford University (1984).

- Pruess, K.: Heat Transfer in Fractured Geothermal Reservoirs with Boiling, Journal of Water Resources Research, vol. 19, no. 1, pp. 201-208, 1983.

- Pruess, K., Calore, C., Celati, R., and Wu, Y. S.: An Analytical Solution for Heat Transfer at a Boiling Front Moving Through a Porous Medium, Int. Journal of Heat Mass Transfer, vol. 30, no. 12, pp. 2595-2602, 1987. 
- Pruess K. and O'Sullivan M.: Effects of Capillarity and Vapor Adsorption in the Depletion of Vapor-Dominated Geothermal Reservoirs, Proceedings: Seventeenth Workshop on Geothermal Reservoir Engineering, Stanford University, Jan. 1992.

- Rhoads, G.H.Jr., and Robinson, E.S.: Determination of Aquifer Parameters From Well Tides, J Geoph Res, Vol 84(B11),(Oct 1979) 60716082.

- Roach, G. F.: Green's Functions, 2nd edition, Cambridge University Press (1982).

- Robinson, E.S., and Bell, R.T.: Tides in Confined Well-Aquifer Systems, J Geoph Res, Vol 76(8), (Mar 1971) 1857-1869.

- Rosa, A. J.: Reservoir Description by Well Test Analysis Using Cyclic Flow Rate Variations, PhD dissertation, Stanford University (1991).

- Stanford Geothermal Program: Quarterly Report for April, May and June, (1992).

- Starkgold, I.: Green's Functions and Boundary Value Problems, John Wiley \& Sons (1979).

- Strobel, C.J., Gulati, M.S and Ramey, H.J.Jr.: Reservoir Limit Tests in a Naturally Fractured Reservoir- a Field Case Study Using Type Curves, JPT, Sept 1976, 1097-1106.

- Theis, C.V.: Earth Tides as Shown by Fluctuations of Water Level in Artesian wells in New Mexico, Intern. Union Geodesy. and Geophysics, Washington D.C. (USGS open file report, 10pp) 1939.

- Udell, K.S.: The Thermodynamics of Evaporation and Condensation in Porous Media, no. 10779, California Regional Meeting of SPE, San Francisco, CA, March 24-26, 1982

- Wanell, M.J., and Morrison, S.J.: Vertical Permeability Measurement in New Reservoirs Using Tidal Pressure Changes, SPE 20532, 65th Annual Technical Conference, New Orleans,(23-26 Sept 1990).

- Whiting, R. L. and Ramey, H. J. Jr.: Application of Material and Energy Balances to Geothermal Steam Production, no. 1949, SPE Annual Conference and Exhibition, Houston, TX, Oct. 1-4, 1967. 
- Witherspoon, P.A., Narasimhan, T.N., and McEdwards, D.G.: Results Of Interference Tests From Two Geothermal Reservoirs, JPT (Jan 1978) $10-16$.

- Woods, A. W. and Fitzgerald, S. D.: The Generation of Vapour in a Hot Rock through Injection of Cold Water, Cambridge Unversity, England, Unpublished report, April, 1992. 